Portland State University

PDXScholar

\title{
The relationship between the use of graphophonic strategy and the success in English vocabulary learning for Chinese students
}

Ching-chih Christine Huang

Portland State University

Follow this and additional works at: https://pdxscholar.library.pdx.edu/open_access_etds

Part of the Applied Linguistics Commons

Let us know how access to this document benefits you.

\section{Recommended Citation}

Huang, Ching-chih Christine, "The relationship between the use of graphophonic strategy and the success in English vocabulary learning for Chinese students" (1992). Dissertations and Theses. Paper 4324. https://doi.org/10.15760/etd.6208

This Thesis is brought to you for free and open access. It has been accepted for inclusion in Dissertations and Theses by an authorized administrator of PDXScholar. Please contact us if we can make this document more accessible: pdxscholar@pdx.edu. 
AN ABSTRACT OF THE THESIS OF Ching-chih Christine Huang for the Master of Arts in TESOL presented February 12, 1992.

Title: The Relationship between the Use of Graphophonic Strategy and the Success in English Vocabulary Learning for Chinese Students.

APPROVED BY THE MEMBERS OF THE THESIS COMMITTEE:

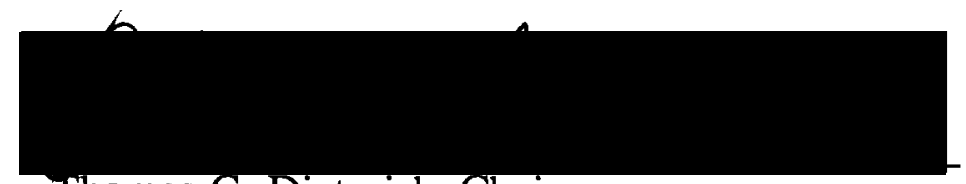

Thomas G. Dieterich, Chair

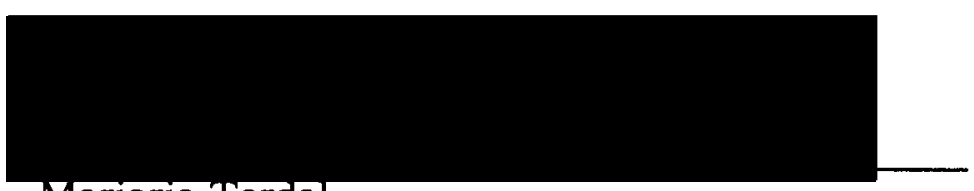

Marjorie Terdal

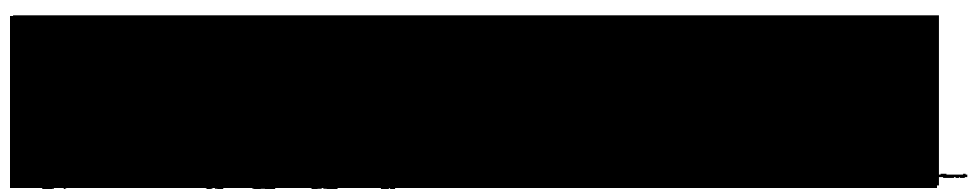

Jeanette S. DeCarrico

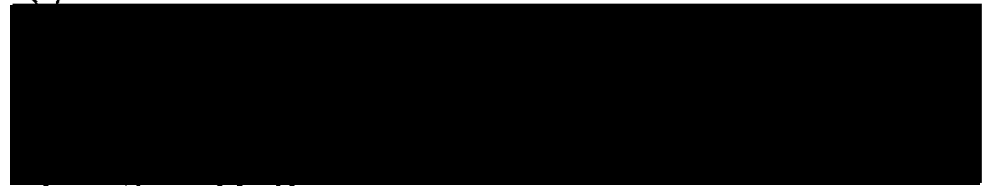

Jonathan 0. Pease

For Chinese EFL learners, the skill of vocabulary learning is one of the most essential elements in their English learning process. Many Chinese students transfer their familiar character-learning strategies, which include shape 
identification and rote memorization, in their English word-learning process. As a result, they may spend time and effort associating the shape, the sound, and the meaning of an English word before they learn and memorize it. Since they do not take advantage of the correspondence between the print and the sound, their vocabulary-learning process seems to be less effective.

This study, following other related research, intended to investigate the question of whether there is a relationship between Chinese EFL students' ability to apply graphophonic strategy in learning English words and the success of their learning. Subjects were first asked to learn selected words according to their own strategies; no hint was given about the pronunciation of these words. They were later required to read these words orally. If subjects used graphophonic strategy in their learning, they would be able to read these words correctly and quickly because they had figured out the pronunciation in the previous learning session. Thus the number of words subjects could pronounce after the learning session and the time they spend in reading the word list provided indicators of their ability to apply graphophonic strategy in learning English words. Subjects' learning success was measured by two vocabulary tests: a short-term vocabulary recall test and a long-term vocabulary recall test.

Two groups of subjects participated in this study. Group A consisted of both male and female students from regular colleges in Taipei, Taiwan. Group B subjects were junior college students, all female, from the same area. These two groups were given exactly the same treatment. 
Four hypotheses were posed:

1a. There will be a significant positive relationship between the number of words pronounced correctly from a previously learned vocabulary list of written words and the number of words answered correctly on a vocabulary test administered immediately after the vocabulary learning session.

1b. There will be a significant positive relationship between the number of words pronounced correctly from a previously learned vocabulary list of written words and the number of words answered correctly on the vocabulary recall test administered two weeks after the vocabulary learning session.

2a. There will be a significant negative relationship between the time used to read the previously learned vocabulary list of written words and the number of words answered correctly on the vocabulary recall test immediately after the learning session.

$2 \mathrm{~b}$. There will be a significant negative relationship between the time used to read the previously learned vocabulary list of written words and the number of words answered correctly on the vocabulary recall test two weeks after the vocabulary learning session.

Group A yielded statistical results which supported all the hypotheses while the results of group B supported hypotheses $1 \mathrm{a}$ and $1 \mathrm{~b}$, but not $2 \mathrm{a}$ and $2 \mathrm{~b}$. Since six out of eight correlations were found significant, it can be concluded that there is a positive relationship between Chinese EFL students' ability to apply graphophonic strategy in vocabulary learning and their learning success. Thus, graphophonic strategy can help Chinese students learn English words more efficiently.

Two additional conclusions are suggested by this study. One, the more a group of subjects is proficient in graphophonic strategy, the more likely there will be a relationship between the use of graphophonic strategy and the success of vocabulary learning. Two, other strategies, like visual identification or rote 
learning, can be effective for English vocabulary-learning in the short run.

However, the use of these "other" strategies may not be as effective as using graphophonic strategy to extend memory retention. Thus, compared to other strategies, graphophonic strategy remains superior in English vocabulary-learning. 
THE RELATIONSHIP BETWEEN THE USE OF GRAPHOPHONIC STRATEGY AND THE SUCCESS IN ENGLISH VOCABULARY LEARNING FOR CHINESE STUDENTS

by

\title{
CHING-CHIH CHRISTINE HUANG
}

A thesis submitted in partial fulfillment of the requirement for the degree of

\author{
MASTER OF ARTS \\ in \\ TESOL \\ Portland State University \\ 1992
}


TO THE OFFICE OF GRADUATE STUDIES:

The members of the Committee approve the thesis of Ching-chih Christine Huang presented February 12, 1992.

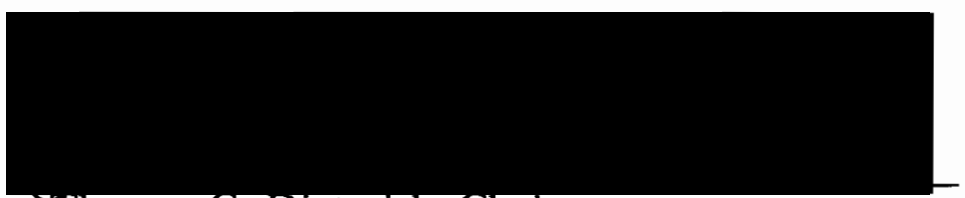

Thomas G. Dieterich, Chair
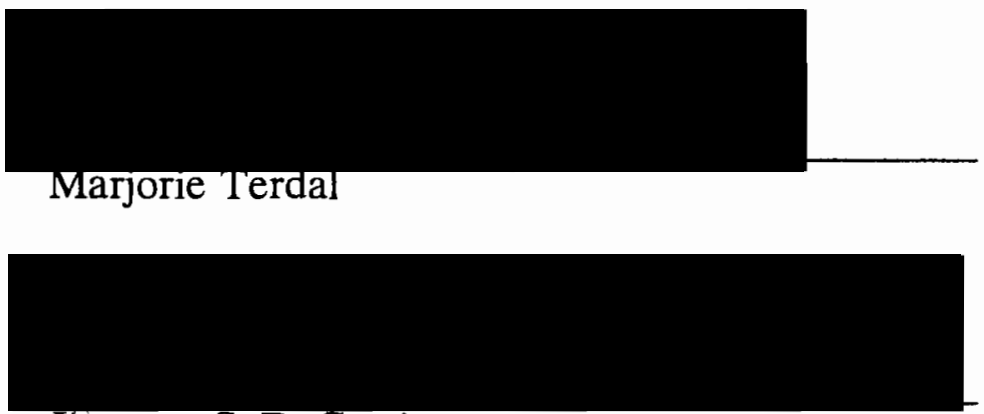

Jeanette S. DeCarrico

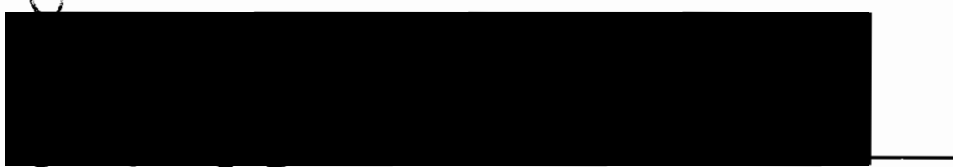

Jonathan O. Pease

APPROVED:

james R. Nattinger, Chair, Department of Applied Linguistics

C. William Savery, Interim Vice Proyøst for Graduate

Studies and Research 
To

my parents 


\section{ACKNOWLEDGEMENTS}

To complete a thesis is like raising a child. The whole process was a difficult, painful, but also a wonderful experience. I was fortunate to have strong support and valuable advice from many people during this "child rearing" stage. My thesis could never have reached its maturity without their help.

I would like to thank professor Thomas G. Dieterich, my thesis advisor, for his kindly help. He provided me with countless suggestions about my research design; also, his professional expertise helped me develop methods of analyzing the data. I was always filled with ideas after I had a meeting with him. Without his support, this thesis could never have been finished.

I also want to thank professor Terdal for her support as a teacher and in my personal life during the most desperate years of my education. With empathy, she listened to my problems and responded with kindness and academic expertise. I was very grateful for her assistance.

Professor DeCarrico's Phonology class taught me the importance of the phonetic rules in vocabulary learning, which inspired the core idea of my thesis. Professor Pease also provided valuable comments to polish my study. I want to thank them for their professional help.

I am particularly grateful to my husband, who, from the very beginning of the thesis writing process, constantly encouraged me and supported me. Also, he 
taught me to use some complicated functions in the computer and helped me to run statistics programs. His efforts reduced my work load to the minimum. Also, I want to thank my friends, Wei-man Hsieh, Mei-li Chen, and Kang-ling Liu, who helped me find the subjects and conduct part of the experiments. All their help has made the completion of my thesis.

Most of all, I want to thank my parents for their endless love. They always gave the best for my education, no matter it cost them. I am particularly thankful for their support. I hope that they can be happy now that I have completed my study, and may they lead happy and long lives. 


\section{TABLE OF CONTENTS}

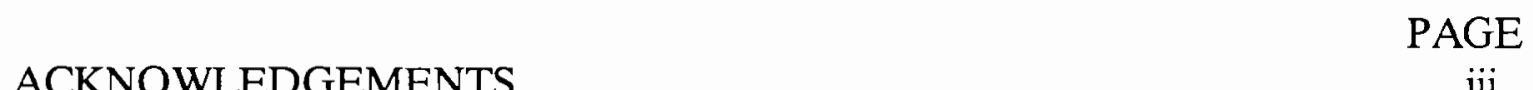

LIST OF TABLES. . . . . . . . . . . . . . . . . . . viii

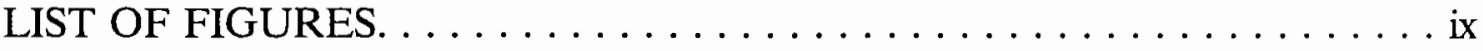

\section{CHAPTER}

I INTRODUCTION $\ldots \ldots \ldots \ldots \ldots \ldots \ldots \ldots \ldots$

Vocabulary Learning in Visual Mode for Chinese

Students ................... 1

The Chinese Way of Word Learning. . . . . . . . 3

The Research Question. .............. . 5

II REVIEW OF THE LITERATURE ............9

Phonetic Vs. Visual Path. . . . . . . . . . . 10

Rule-Governed Vs. Word-Specific Processing . . . . . . 14

Strategies of Learning and Reading Chinese Words. . . . 18

The Role of Phonetic Recoding in Reading Chinese. . . . .20

Cerebral Lateralization Effects. . . . . . . . . . . . 21

Learning English Words for Chinese Students . . . . . . 24

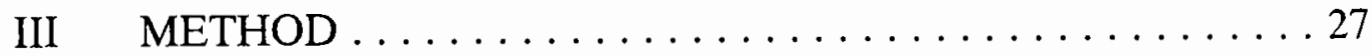

Background and General Design of the Study . . . . . 28

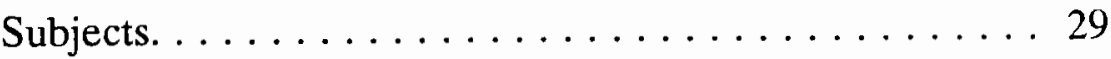


Materials ...................... 30

Research Design and Procedures .......... 32

Scoring the Oral Reading Performance ......... 35

Estimating the Oral Reading Time $\ldots \ldots \ldots \ldots 38$

Summary. . . . . . . . . . . . . . . . . . 39

IV $\quad$ RESULTS $\ldots \ldots \ldots \ldots \ldots \ldots \ldots \ldots \ldots \ldots \ldots \ldots \ldots$

General Statistics ................. 41

Relationship between Oral Reading Scores and

Short-Term Vocabulary Test Scores . . . . . . . . . . 44

Relationship between Oral Reading Scores and Long-Term Vocabulary Test Scores . . . . . . . . 45

Relationship between Oral Reading Time and

Short-Term Vocabulary Test Scores . . . . . . . . . 51

Relationship between Oral Reading Time and

Long-Term Vocabulary Test Scores. . . . . . . . . . . 55

V INTERPRETATION OF RESULTS. . . . . . . . . . 59

Interpretation of the Correlation between Oral Reading

Scores and Short-Term Vocabulary Test Scores. . . . . . 60

Interpretation of the Correlation between Oral Reading Scores and Long-Term Vocabulary Test Scores . . . . . . 61

Interpretation of the Correlation between Oral Reading Time and Short-Term Vocabulary Test Scores ... . . . 64

Interpretation of the Correlation between Oral Reading Time and Long-Term Vocabulary Test Scores . . . . . . . .65

Group Differences between Group A and Group B. . . . 66

Limitations of Experimental Design. . . . . . . . . 68 
Summary $\ldots \ldots \ldots \ldots \ldots \ldots \ldots \ldots \ldots \ldots \ldots \ldots \ldots \ldots \ldots$

VI CONCLUSIONS AND RECOMMENDATIONS . . . . . . . 72

Implication for EFL Teaching. . . . . . . . . 76

Suggestions for Further Research. . . . . . . . . . . . .77

REFERENCES . . . . . . . . . . . . . . . . . . . . . 79 APPENDICES

A THE VOCABULARY LEARNING LIST. . . . . . . 83

B SAMPLE OF THE VOCABULARY LEARNING BOARD . . 85

C THE SHORT-TERM VOCABULARY RECALL TEST . . . . 87 


\section{LIST OF TABLES}

PAGE

TABLE

I Results of the Oral Reading Performance for Group A. . . . . .42

II Results of the Oral Reading Performance for Group B. . . . . . 43

III Results of Vocabulary Tests for Group A . . . . . . 43

IV Results of Vocabulary Tests for Group B . . . . . . . . 44

V Correlation between Oral Reading Scores and Short-Term Vocabulary Test Scores ................. 45

VI Correlation between Oral Reading Scores and Long-Term Vocabulary Test Scores . . . . . . . . . . . . . . 48

VII Correlation between Oral Reading Time and Short-Term Vocabulary Test Scores . . . . . . . . . . . . 52

VIII Correlation between Oral Reading Time and Long-Term Vocabulary Test Scores .................... 56 


\section{LIST OF FIGURES}

PAGE

FIGURE

1. Relationship between Oral Reading Scores and Short-Term

Vocabulary Test Scores for Group A. . . . . . . . . . . . . 46

2. Relationship between Oral Reading Scores and Short-Term

Vocabulary Test Scores for Group B . . . . . . . . . 47

3. Relationship between Oral Reading Scores and Long-Term

Vocabulary Test Scores for Group A . . . . . . . . . . . . . .49

4. Relationship between Oral Reading Scores and Long-Term

Vocabulary Test Scores for Group B . . . . . . . . . . 50

5. Relationship between Oral Reading Time and Short-Term

Vocabulary Test Scores for Group A . . . . . . . . . . . . .53

6. Relationship between Oral Reading Time and Short-Term

Vocabulary Test Scores for Group B. . . . . . . . . . . 54

7. Relationship between Oral Reading Time and Long-Term

Vocabulary Test Scores for Group A. . . . . . . . . . . . 57

8. Relationship between Oral Reading Time and Long-Term

Vocabulary Test Scores for Group B. . . . . . . . . . 58 


\section{CHAPTER I}

\section{INTRODUCTION}

Vocabulary knowledge is one of the most basic elements in second language learning. The first experience of beginning learners is to learn new words. As more and more structures and concepts of the second language are introduced, it becomes necessary for students to acquire more words to match the growing amount of language input. Even after second language students have learned enough words to deal with the demands of language classrooms, they still need to expand their vocabulary to meet the requirements of the real world. This "real world" language environment can also include the second language learner's native country where the target foreign language is found only in print. For example, specialists or engineers have to know enough technical terms and common words in order to understand advanced professional reports written in a second language. Thus from the very beginning to the advanced level, vocabulary learning is a continuous process for every second language student.

\section{VOCABULARY LEARNING IN VISUAL MODE FOR CHINESE STUDENTS}

For Chinese students in their own countries, knowing enough vocabulary is necessary especially for higher education and beyond. In Taiwan, many college professors use textbooks from the United States as reading material for their 
students. These books, ranging from accounting principles to high-tech reports, contain numerous English words which may be unfamiliar for native Chinese speakers. Reading and learning are difficult for these students if they do not know sufficient vocabulary words. The need for English vocabulary skill even goes beyond college. People in the business or engineering fields, especially professional college graduates, usually need to read documents written in English for international trade and technological purposes. Without enough vocabulary knowledge, these people would waste most of their energy checking dictionaries before they could understand every piece of information. Since Chinese learners of English mostly encounter vocabulary items in print, the focus of this thesis is on vocabulary learning through the visual mode instead of through the auditory mode. In other words, this thesis deals with word learning from printed material. The popular concept of learning vocabulary through context indeed provides a good principle for learning in a broader sense. However, Chinese students may also need specific learning skills which general principles like "learning through context" cannot provide. For example, how do Chinese students learn, memorize, and recognize the meaning of a new English word? Do they learn by the shape of a word, by its spelling, or by its sound? These questions may not cause any problem for ESL students who come from alphabetic language backgrounds, because these students can easily apply their first language learning experience to learn an English word. However, the learning process on this fundamental level can differ from one writing system, and one culture, to another. 
With a totally different educational tradition and writing convention, Chinese students may not know how to learn new words in English very efficiently without proper instruction.

\section{THE CHINESE WAY OF WORD LEARNING}

The Chinese writing system consists of thousands of logographic characters, each of which represents a spoken syllable, usually with a specific, self-contained meaning. Unlike in alphabetic languages, pronouncing a Chinese character analytically through its strokes or its component units is usually impossible. Since there are almost no graphophonic rules on the character level, in many cases Chinese readers are unlikely to identify a character in print if they have never seen it before (even if they have heard the word corresponding to that character a thousand times previously).

Chinese children in Taiwan learn a character by identifying its distinctive shape and copying it down stroke by stroke. Their homework assignments always include the practice of character writing along with the writing of phonetic representation of each character. In other words, students learn to associate each individualized configuration of a character with its sound (through its phonetic symbols or through speaking it) and its meaning. Since graphophonic rules are not available, rote memorization is used to identify and practice the strokes of each unique character. This totally different learning approach may affect the way Chinese students learn English words in the visual mode. 
Adult native Chinese speakers may possibly apply their familiar rote memorization and visual identification learning skill to the learning of English words. Based on my personal experience, observation, and discussions with other Chinese students, many Chinese learn written English words through rote memorization. Four steps are usually used to memorize a word if the students know its pronunciation: looking at the target word, pronouncing it, reading its Chinese translation, and spelling the word orally while simultaneously writing down the spelling. Apparently, this type of learners treats English words as logographic characters. In the first, second, and third steps, students try to associate the shape of the word with its sound and meaning; in the fourth step, students memorize a word letter by letter just as they memorize a character stroke by stroke. If the pronunciation of a word is not provided (which is usually the case), Chinese students would not try to pronounce the word themselves through phonetic rules. They usually omit the second step (pronouncing the word) and still try to memorize a written word without knowing its sound. They learn from their firstlanguage learning experience to associate between meaning and shape, sound and shape, and meaning and sound. The idea of analyzing the spelling-sound relationship before they learn a word seems uncommon for the Chinese students. The pronunciation of a word, if given to them by their English teachers, may help the learning process only in the sense that the sound of a word gives one more association to the visual configuration as a whole.

Both the word-specific, rote memorization learning style and the visual 
learning strategy show the underuse of the graphophonic strategy in processing a written language. This does not mean that Chinese students do not have any graphophonic knowledge available; it simply indicates that they may not use a graphophonic strategy in word learning as much as native speakers of English do. However, whether this Chinese way of learning is effective in learning English words remains unknown. Their strategy may be very effective given the fact that the shape of a word does not need to be transferred into sound before a student can learn to recognize it visually. Since Chinese students are very familiar with this strategy, it may be easier for them to learn words in their own way than with any "foreign" method. On the other hand, this strategy may be very ineffective since it does not take advantage of graphophonic correspondences of English. Most research (discussed in Chapter II) on English word learning and reading for native speaking children has found that knowing graphophonic correspondences plays an important role in learning to recognize written words. Thus it is possible that the knowledge of graphophonic strategy could help Chinese students learn words more efficiently.

\section{THE RESEARCH QUESTION}

The major question addressed in this thesis is whether or not there is a relationship between the Chinese EFL learners' ability to apply graphophonic knowledge in learning words and their success in vocabulary learning. Since native English speaking children tend to learn printed words better if they possess the 
knowledge of English graphophonic correspondences, we expect that Chinese students can also benefit from the use of these rules in word learning. If this assumption is true, there should be a significant positive correlation between students' overall success at vocabulary learning and their graphophonic knowledge of the words learned (as measured by speed and accuracy on an oral reading test). If the visual/rote memorization strategies are equally or more effective, then there should be no significant positive correlation between graphophonic knowledge and vocabulary learning success.

In order to investigate the relative effectiveness of these strategies experimentally, several assumptions will be made. First of all, students who know more about how to pronounce a word after a learning session (without any pronunciation instruction) are assumed to make more use of graphophonic strategy in their learning than students who do not. On the other hand, students who can not manage to pronounce any words correctly after the learning session are assumed not to use graphophonic strategy. The underlying philosophy is that after students apply graphophonic strategy to memorize a word, they will naturally know how to pronounce the word. If students are only dimly aware of the graphophonic correspondences, they will pronounce the words less correctly and less quickly. Those who do not know graphophonic correspondences simply are not able to pronounce a word without instruction; thus they are most likely to resort to the rote learning and visual identification strategy to memorize the words. 
The research hypotheses are:

1. Relationship between number of words read correctly and the number of words memorized:

1a. There will be a significant positive relationship between the number of words pronounced correctly from a previously learned vocabulary list of written words and the number of words answered correctly on a vocabulary test administered immediately after the vocabulary learning session.

1b. There will be a significant positive relationship between the number of words pronounced correctly from a previously learned vocabulary list of written words and the number of words answered correctly on the vocabulary recall test administered two weeks after the vocabulary learning session.

2. Relationship between the time used to read a word list and the number of words memorized:

2a. There will be a significant negative relationship between the time used to read the previously learned vocabulary list of written words and the number of words answered correctly on the vocabulary recall test immediately after the learning session.

2b. There will be a significant negative relationship between the time used to read the previously learned vocabulary list of written words and the number of words answered correctly on the vocabulary recall test two weeks after the vocabulary learning session.

All of the above mentioned hypotheses state that the ability to use a 
graphophonic strategy will correlate with the success of vocabulary learning. If this overall hypothesis is supported, it will strongly suggest that the successful Chinese learners of English vocabulary know how to apply graphophonic strategy in learning English words. Thus an English teacher should be encouraged to teach Chinese students the letter-to-sound correspondences in written English. If no significant relationship is found, it may indicate that transferring the Chinese character learning strategies could be equally effective as using phonetic strategy in learning visually presented English words. In this case, the teacher may encourage students to transfer their learning strategies in L1, namely, visual identification and rote memorization, to learn English words. 


\section{CHAPTER II}

\section{REVIEW OF THE LITERATURE}

There are several paths a learner can use to derive meaning from printed English words. One of the most common paths is to use phonetic (auditory) information to get to the meanings of printed words. The fact that most native speakers can identify the meaning of an unlearned printed word through pronouncing it (providing that the word was in their spoken or auditory lexicon) indicates that the ability to use graphophonic strategy plays an important role in word recognition. The learner can also use the visual pattern of a word to recognize it. This strategy is most obvious when learners need to distinguish between two printed homophones in an ambiguous context. For example, the words "pair" and "pear" should be recognized as the same if readers transform the print into sound; however, readers usually can distinguish the sentence "I want to buy a pear" or "I want to buy a pair" even in isolation without much difficulty. Thus both the phonetic path and the visual path exist in our decoding skills. The only difference is the frequency and effectiveness of those two different strategies being used.

Research on native English readers has demonstrated the existence and effectiveness of both visual and graphophonic strategies in reading and word identification. In terms of which strategy is better for learning words, most 
research on native English-speaking children has found that superior learners are those who have the ability to apply print-to-sound rules in vocabulary learning and reading. It could be expected that EFL learners could also benefit from the regular English graphophonic rules in learning vocabulary. However, in contrast, research on reading of Chinese logographic writing has found that the reading of a single Chinese character usually does not need an intermediate phonetic stage; instead, visual identification seems to be more important. Since Chinese students are trained to learn words visually, they probably would transfer their visual learning strategy in learning English vocabulary. This thesis thus investigates the question of whether Chinese students can benefit from applying graphophonic rules in learning English words. This chapter will discuss research results in visual and graphophonic strategies in English word identification and reading, as well as reading of Chinese characters.

\section{PHONETIC VS. VISUAL PATH}

Evidence that a direct print-to-meaning path exists in English was provided by Baron (1973). He found that subjects could classify, as not making sense, phrases such as "tie the not" or "it's knot so" just as quickly as they could classify phrases such as "I am kill" or "ill him." If subjects had transferred the printed words into speech representations, they would presumably take longer with the former phrases, which would make sense when the phrases were read orally. On another experiment, subjects were asked whether or not phrases sounded sensible 
no matter how they looked. Subjects responded faster and made fewer errors on the phrases which both looked and sounded sensible. This result suggested that visual strategy is also effective in the process of reading.

Another kind of experiment dealing with the role of visual processing indicates that readers also identify a word through the word's visual shape. Brooks (1977) trained subjects to search for first names or place names in mixed typed cases (such as IInDa). In the follow-up task, they were either asked to search for the same name category with different letters capitalized ( $\mathrm{LiNdA}$ ), or for a different name category with unchanged stimulus type (such as kEnYa). The result showed that typography had an effect for the reading task when the stimulus pattern was changed, but not when the search category was changed. Thus, some learning must be specific to the form of the word. Similarly, Baron (1977) showed that words were read aloud more quickly in their familiar forms (e.g., Tom, top) than in the unfamiliar forms (tom, Top). Clearly the evidence shows that aside from knowledge of the alphabet and the sounds of letters, the visual form of a word also plays an important role in word identification.

Other experiments demonstrated the role of phonological processing. One kind of experiment deals with the effect of phonemic similarity on the recall task. In presenting a string of letters for immediate recall, Conrad (1964) observed that the letter P was more likely to be misrecalled as B, a letter similar in sound, than as the letter F, a letter similar in shape. Because the sound caused the confusion, the researcher concluded that it was the sound, rather than the shape, that was 
stored in short term memory. Another kind of experiment measured the influence of sound similarity in a sentence judgement task. Baddley and Lewis (1981) asked subjects to read rhyming sentences such as "Crude rude Jude chewed his stewed food" or semantically equivalent but phonemically dissimilar control sentences such as "Rough curt Jude ate his plain boiled meal." The subjects were to judge whether the sentence is semantically permissible or not. The researchers found that the mean classification time was significantly greater for the rhyming sentences than for the non-rhyming sentences. All the above evidence suggests that the phonological route is a preferable way to get and store meaning for reading English.

Another experiment (Levy, 1975), supporting the existence of a phonetic stage, involved a distracting task to prevent subjects from using phonetic recoding strategies. Levy required her subjects to silently read a set of three thematically related sentences with or without a concurrent task of counting out loud. After each sentence, the subjects were given a test sentence; they needed to judge whether the test sentence was one they had just read. Levy examined the role of phonetic mediation in reading by comparing her subjects' performance in each situation. She found that their recognition accuracy was reduced dramatically by the additional requirement to count out loud. This result suggested that the task of counting interfered with the phonetic recoding process in reading which plays a role in maintaining words in memory for the purpose of sentence comprehension.

There are also experiments dealing with the role of phonetic recoding for 
beginning readers (Liberman, Shankweiler, Liberman, Fowler, and Fischer, 1977). The researchers divided children into superior, marginal, and poor readers based on the children's scores on a word recognition test. Each group of subjects was asked to remember letter strings of rhyming consonants and nonrhyming consonants. They were also given an immediate recall test and a delayed recall test. The results showed that phonetic similarity interfered with immediate recall for all the children; but this effect was much greater for the superior group than for the inferior readers. Besides, for the superior readers, the interposition of a delay interval steeply increased errors of recall of the rhyming strings but produced no effect on the recall of nonrhyming strings. For the poor readers, however, there was no interaction of the effects of rhyming with delay. The researchers supposed that the phonetic similarity of the rhyming strings caused interference with rehearsal during the delay interval. The results suggested that the better recall of the superior readers was due to their more efficient use of phonetic recoding, a strategy that ordinarily worked to their advantage, but not in the special case of rhyming strings.

Some of the above evidence shows the effectiveness of a visual path in word identification, other evidence shows the effectiveness of a phonological path. However, none of the evidence proved that the other path is ineffective in word learning and reading. There are other experiments showing that either path can be available and effective under certain circumstances. Hardyck and Petrinovich (1970) supported the effectiveness of both paths by monitoring subjects' 
subvocalization behavior while reading. Subvocalization is a neuromotor activity in the vocal tract during silent reading, and it is taken to indicate the use of a graphophonic identification strategy. The researchers taught some subjects to eliminate their habitual subvocalization behavior while reading. After reading two essays of different degrees of difficulty, this experimental group's performance on reading comprehension tests was compared with the performance of control groups whose subvocal speech was not suppressed. The results indicated that the groups did not show much difference in comprehending easy materials, but the non-vocalizing group performed worse on difficult materials. This result suggested that both visual and phonological paths exist in reading; readers adopt different recognition strategies under different task conditions. Baron and Treiman (1980) summarize the evidence as follows:

In sum, any reasonable path that has been proposed seems to be used in at least some task involving reading. In any reading task, it seems, all paths that could be used are used. Although further research may discover a task in which this is not so, there is good theoretical reason to think that parallel use of multiple paths will be the rule rather than the exception in complex tasks such as reading. (p. 175)

\section{RULE-GOVERNED VS. WORD-SPECIFIC PROCESSING}

Readers differ in their use of visual or phonological strategies; they also differ in their use of phonetic rules or word-specific associations in reading a word. Two kinds of processes may be used to read an English word. One process involves spelling-sound rules. In using such a process, people take advantage of 
the regular correspondences that exist between the phonological (or sound) forms of words and their written forms. Although the spelling-sound rules of English have exceptions, English orthography still allows the reader to approximate the pronunciation of a word. A second process involves word-specific associations. These are rote associations between individual printed words and their sounds (or meanings).

The clearest evidence for individual differences in reading was provided by Baron and Treiman (1980). In their study, children were asked to read three sets of word lists: a regular word list containing words which follow the regular English phonetic rules; a list of exception words which violate the rules; and a nonsense word list containing non-words with English spellings which follow the phonetic rules. The ability to pronounce nonsense words is an indication of children's ability to use phonetic rules in reading. The ability to pronounce exception words, on the other hand, indicates children's ability to use word-specific associations in word learning. Thus children who rely on graphophonic rules should do better at pronouncing nonsense words than reading exception words since such children tend to use orthographic rules in pronouncing the exception words. A child who uses the word-specific association rather than general rules would be expected to read many of the exception words and few of the nonsense words correctly. If individuals differ in whether they rely on rules, the correlation between $\mathrm{N}$, the number of nonsense words correct, and $\mathrm{E}$, the number of exception words correct, should be the lowest of the correlations, since these scores reflect different 
abilities. The results showed that the correlation between $\mathrm{N}$ and $\mathrm{E}, \mathrm{N}$ and $\mathrm{R}$, and $\mathrm{E}$ and $\mathrm{R}$ are $0.49,0.88$, and 0.70 , respectively, demonstrating individual difference in reading strategies.

One interesting question concerning the effect of different reading strategies on vocabulary development is what kind of learner is superior in acquiring the new language. Liberman, Shankweiler, Liberman, Fowler, and Fischer (1977) believed that the use of word-specific path is a result of inability to make phonetic segmentation; thus the children who can successfully segment the phonemes (which is harder than segmenting into syllables) are better learners. In order to test this point, these researchers formed a game requiring children to tap a wooden dowel on the table marking the number of segments (phonemes in the case of one group, syllables in the other) in a list of test words. The results showed that test words were more readily segmented into syllables than into phonemes across all age levels. In follow-up testing in the second school year, the researchers found that half of the children in the lowest third of the class in reading achievement had failed the phoneme segmentation task the previous June; on the other hand, there had been no failures in phoneme segmentation among the children who scored in the top third in reading ability. This experiment suggested that phonetic segmentation, which forms the base of phonetic processing, is necessary for the beginning learners of English; inability to segment the phonemes (which will lead to the inability to use rule-based processing) may result in learning difficulty. 
The experiment by Baron and Treiman cited above showed that the ability to read regular words, an ability reflecting a child's vocabulary capability, correlates more with the reading of nonsense words than with the exception words. This result indicates that rule-users are the superior learners of English words, at least at the beginning learning stage. Another experiment by Baron and Treiman (1980) also provides evidence in favor of the rule-users. The researchers selected pairs of children who scored equally at reading regular words, but with one child older by two years. Within each pair, then, one child had reached the given reading level more quickly than the other. The younger children were found more accurate at reading nonsense words and less accurate at reading exception words than the older children. This result suggests that the younger children's superior skill in spelling-sound rules helped them to learn words more efficiently. From the above evidence, it may be concluded that the use of spelling-sound rules may play a causal role in learning words.

It seems fair to conclude that children who have a graphophonic strategy available are better at vocabulary development, word identification, reading and learning to read. Children who master spelling-sound rules will be able to identify many printed words that are in their spoken vocabularies, even if they have not seen the words in print before. In writing, they will make phonetically reasonable errors that allow teachers to identify the intended word. The children who do not know many graphophonic rules will make spelling mistakes that are difficult to interpret (Treiman and Baron, 1983). Thus a teacher's task in teaching 
vocabulary should include teaching students to acquire the graphophonic rules embedded in the English orthography.

\section{STRATEGIES OF LEARNING AND READING CHINESE WORDS}

Generally speaking, the Chinese writing system is logographic, a type of orthography where individual written signs represent words or morphemes of the spoken language (Gleitman and Rozin, 1977). The orientation and the number of strokes that form the basis of a character do not bear much relationship to the sound of the spoken word. Although researchers like Wang (1981) have pointed out that most Chinese characters have a phonetic component which provides clues to pronunciation, the success rate of using a base character to pronounce another character is estimated to be low (Tzeng, 1983). Since the sound of a word and its form are for the most part arbitrarily paired, beginning Chinese learners must associate several thousand logographs with their pronunciations without much aid from the orthographic system.

Chinese characters map onto speech at the level of words rather than phonemes. Since there is an arbitrary one-to-one correspondence between the sound and the shape of every single character, the beginning readers of Chinese are facing a more concrete learning situation than those who are learning the alphabetic writing system (Tzeng and Hung, 1980). Rozin, Ponitsky, and Sotsky (1971) supported this point by showing that a group of native English-speaking second-grade school children with serious reading problems were able to make 
rapid progress in learning and reading sentences written in Chinese characters.

With the above information, it is not unreasonable to conjecture that the processing strategies for reading Chinese may be very different from the strategies used in reading English, at least at the word level. Treiman and Baron (1981) also found that speech recoding is used less by readers of Chinese. Native speakers of English and Chinese were asked to silently read sentences in their own languages. The results indicated that readers of English took longer and made more errors in judging the falsity of homophonic sentences (A pair is a fruit.) relative to control sentences (A pier is a fruit.) than do readers of Chinese with comparable sentences in Chinese. This result suggests that the holistic nature of Chinese characters may induce the use of word-specific processing while the phonological aspect of English alphabet encourages the use of phonological rules in reading.

The next logical question is whether phonetic recoding is present in reading Chinese passages. Chinese reading does not involve analytic phonological processing below the word level because each Chinese character is a whole unit by itself. However, whether Chinese use phonetic coding at levels higher than the word remains an uncertain issue. Many researchers have claimed that Chinese use a direct visual strategy in reading (Liu, 1978; Shwedel, 1983; Wang and Earle, 1972). The rationale, aside from the fact that Chinese writing lacks letter-sound relationship, also includes the fact that children from different dialects have to learn the same characters. However, there was no experimental evidence to 
support these claims.

\section{THE ROLE OF PHONETIC RECODING IN READING CHINESE}

Generally speaking, since a Chinese character is a holistic unit without any letter-to-sound correspondence, the processing of individual characters usually does not involve phonetic recoding. Tzeng and Huang (1980) have done a study to support this viewpoint. Chinese subjects were asked to make decisions about strings of characters with or without a concurrent shadowing task. The shadowing task, in which subjects had to repeat digits in Chinese, was designed to disrupt phonetic recoding. The subjects' task was to make one of three decisions about two characters: 1) they share an identical radical (graphemic), 2) they rhyme with each other (phonetic), or 3 ) they are synonyms (semantic). The results indicated that only the phonetic decision was affected greatly by the shadowing task. Both the graphemic and semantic decisions seemed to suffer only the general disruption caused by the shadowing task. Thus, it can be concluded that for single characters lexical access does not require the intermediate stage of phonetic decision.

Shwedel (1983) has further suggested that Chinese may never use $\checkmark$ phonology to read if they have not learned to read any alphabetic script. In his experiment, subjects were asked to recall lists of Chinese characters, including homonym sets, visually similar character sets, and control sets. He found that university students, proficient at reading both English and Chinese, apparently did much worse in homonym sets than in other sets. The other group, workers who 
had no knowledge of English, were apparently no more affected by the phonological similarity than by the visual similarity. The result suggests that the university students used phonology in reading characters while the workers did not. Since the people who have never learned English do not show much influence by phonological similarity, it is possible that phonological recoding is not intrinsic to the Chinese system.

\section{CEREBRAL LATERALIZATION EFFECTS}

The term lateralization refers to the specialization of the left or right hemisphere of the brain for different functions. In most right-handed persons, for example, speech is generally lateralized in the left cerebral hemisphere. The two hemispheres have different but complementary processing modes. In general, sequential, analytic and phonetic processing are the preferred modes of the left hemisphere; simultaneous, holistic, and imagistic processing are the preferred processing modes of the right hemisphere (Taylor, 1987). With the phonetic nature of an alphabetic language, English orthography usually is processed in the left hemisphere (Sperry, 1969). Kimura (1973) also found in her dichotic listening experiments that subjects were quicker and more accurate in identifying speech sounds processed in the left hemisphere than the right. Similarly, in visual hemifield experiments, in which English words were presented to either the left or the right of a central fixation point, Mishkin and Forgays (1952) found a different accuracy of recognition, favoring words presented to the right of the fixation point. 
This finding has been termed the right-visual-field, RVF, superiority effect, indicating the left-hemisphere superiority of language processing.

The result of the left-hemisphere superiority in alphabetic language processing, however, might not generalize to a logographic language like Chinese. Since Chinese characters usually cannot be read through a phonetic blending process, it has been suggested that reading Chinese characters is much more like a visual pattern recognition task, a task presumably carried out in the right hemisphere. Consequently, one would expect a left visual field, LVF, superiority (which indicates a right hemisphere superiority), if there is indeed a visual lateralization effect.

Experiments on Chinese characters and Japanese Kanji (the Japanese version of Chinese characters) have supported the above expectations on the single character level. Hatta (1977) reported an experiment measuring recognition accuracy of Kanji characters. Left visual field superiority was found for both high and low familiarity Kanji characters, suggesting that Kanji characters are processed in the right hemisphere. Tzeng, Hung, and Cotton (1979) followed Hatta's procedure but with an additional manipulation. They broke the test characters into phonograms -- those characters that contain a certain base character as a clue to their pronunciation, and pictograms -- those characters that are pictographic in origin. A strong LVF superiority effect was found with both kinds of characters. This result suggests that a Chinese character is processed mainly in the right hemisphere regardless of whether the character contains any phonetic clue. 
Another kind of experiment concerning the difference in processing strategies across languages is closely related to the role of Stroop Interference. In the test that bears his name, Stroop (1935) found that subjects were much slower in naming colors when the colored ink spelled the name of a conflicting color. For example, if RED GREEN BLUE YELLOW were, respectively, printed with conflicting inks of blue, yellow, red and green, then naming the colors, "blue," "yellow," "red," "green" would be considerably slower than naming the same colors when they formed nonword color patches such as rectangles. In performing this task readers become painfully aware of reading the print and considerable mental time and effort must be expended in suppressing what they have read in favor of naming the color. According to Biederman and Tsao (1979), this interference effect has been shown in many languages. The question is whether the magnitude of interference (the time taken to name the color with the incongruous or conflicting word minus the time needed to name the color of the unmarked patch) differs across scripts. This should provide a clue to the processing mechanism of Chinese.

Experiments of Stroop interference on Chinese subjects have been conducted by several researchers. Biederman and Tsao (1979) found that Chinese subjects performing the color-naming task showed greater interference than did English speaking readers performing an English version of the same task. The researchers speculated that reading Chinese characters and the use of color information may be competing for the same perceptual capacities whereas reading 
English, a left hemisphere activity, and color naming could, by this account, be executed by different mechanisms. Two later experiments (Tsao, Wu, and Feustel, 1981; Tsao, Feustel, and Soseos, 1979) supported this point. With the Chinese subjects, there was significantly more interference between the color and the irrelevant color name when the stimuli were presented in the LVF rather than the RVF. This result is in direct contrast with the results from the study using English-speaking subjects, in which there was more Stroop interference in the RVF. The above evidence strongly suggests that there are fundamental differences in the perceptual demands of reading Chinese and English. A reader of English cannot refrain from applying an abstract rule system to the word; a reader of Chinese may not be able to refrain from configurational processing of the ideograph (Biederman and Tsao, 1979).

\section{LEARNING ENGLISH WORDS FOR CHINESE STUDENTS}

From the experimental findings on the cerebral lateralization effect and on the phonetic recoding of Chinese characters, it can be concluded that the processing of Chinese characters differs from the processing of English words greatly on the character (word) level. In order to identify a Chinese character, readers must recognize the character as a whole unit (word-specific strategy) and identify it by its visual shape (visual strategy). As Chinese students learn English vocabulary, they may also treat each English words as a holistic unit. Zhou (1988) has used an "envelope theory" to explain the way Chinese students recognize an 
English word. He found that some Chinese students read $\overline{c o n d u c t}$ as $\overline{c o n t a c t}$ or signing as singing Because two words shared the same "envelop feature", Chinese students, accustomed to recognizing words visually, would be easily confused by the similar shape of these words. If students had applied graphophonic strategy to read English words, errors like these could have never occurred. Since this visual identification strategy differs greatly from the phonetic processing in reading English, transferring visual strategy to learn English words may not be effective.

Aside from the orthographic difference, there is another reason to believe that Chinese students may use a word-specific path in reading English. The Chinese educational system has long emphasized the importance of memory. From the very beginning of their schooling, children have to learn characters by rote memorization. Later they are also required to remember important and famous texts. The discipline of memorizing and learning by rote is believed to be an essential characteristic necessary for successful language learning in China (Scovel, 1983, Fischer-Kohn, 1986). Children even are taught to memorize without being asked to understand the meaning of the text (Field, 1985). Under this educational system, Chinese students, who take rote-memorization of characters as the only way to learn Chinese words, may very likely try to memorize the shape and the spelling of English words without considering the phonetic rules. They may also be reluctant to try to learn the orthographic rules by themselves.

Given the fact that graphophonic skills are one of the most important factors in learning English, and the experimental results showing that superior 
learners of English words (for the beginners) are the ones who use graphophonic rules to read and to learn, Chinese students' lack of knowledge of rules may slow down the normal learning process of English. Thus Osborne-Wilson, Sinatra, and Baratta (1989) have pointed out that the major learning task for native Chinese speakers to learn to read English is to master the sub-lexical sound-symbol correspondence of English. This thesis, following other related research, intends to see if there is a relationship between Chinese students' ability to use graphophonic correspondences and their success at learning and retaining English vocabulary. 


\section{CHAPTER III}

\section{METHOD}

It can be concluded from Chapter II that graphophonic knowledge is essential in successful learning of English words for native speaking learners. However, whether Chinese learners of English could benefit from the graphophonic strategy remains a question. This study looked at Chinese EFL learners and investigated the relationship between their ability to apply graphophonic rules in vocabulary learning and their learning success. If any significant relationship can be found, hopefully the result can shed some light on the vocabulary teaching method for speakers of logographic languages.

Two heterogeneous groups of subjects participated in this study. They were asked to use their own familiar strategies to learn the assigned words. They were later required to read the words orally, to take an immediate vocabulary recall test, and finally, to take a long-term vocabulary recall test. Whether students used graphophonic strategy to memorize words was tested by their ability to read these words orally after the learning session. Subjects' learning achievement was measured through the vocabulary recall tests. 


\section{BACKGROUND AND GENERAL DESIGN OF THE STUDY}

This study originally was inspired by the work of Baron and Treiman (1983). These two researchers used the ability to read nonsense words correctly as an indication of the degree of graphophonic skill a student possessed. My study borrowed the concept of testing the extent to which students can apply graphophonic strategy by giving students words which they have never heard before to read. The number of unheard words students could read correctly served as an indicator of the degree of graphophonic maturity they achieved.

There was a learning session in which students learned assigned unknown words without the assistance of a teacher's pronunciation, although in contrast to the Baron and Treiman study, real words were used as an added motivator for students to learn. If nonsense words had been given, students might not have been interested in learning; the learning process then would not be effective no matter what strategy students used to learn the words. After the learning session, students were required to read the previously learned words orally. If a subject did not pronounce any of these unheard words correctly, he or she can be assumed to be totally unfamiliar with the graphophonic correspondences; thus he or she must have applied strategies other than graphophonic skills in learning. It is also assumed that the subjects who could pronounce all words correctly and quickly must have known the English graphophonic correspondences very well. Falling between the two extremes, each subject's level of graphophonic ability could be measured through the accuracy and speed of their oral performance on 
word reading.

If the graphophonic strategy can help Chinese students in learning new words more effectively, there should be a significant positive correlation between the number of words read correctly and the vocabulary test scores. Also, there should be a significant negative correlation between the length of time used to read the words and the vocabulary test scores. If visual strategy and rote learning, the learning methods that Chinese students are more familiar with, are the most efficient way for Chinese students to learn vocabulary, reverse correlations should be found for the above two situations.

\section{SUBJECTS}

All of the subjects were college or junior college students in Taipei, Taiwan. The official language for their education is Mandarin Chinese, which is also the official language in China. Two groups of subjects participated in this study. The first group, group A, consisted of 50 college freshmen (both male and female) from National Cheng Chi University and Ming Chuan College in Taipei, Taiwan. These subjects had studied English for approximately six years in junior high and high school. The second group, group B, consisted of 43 female junior college students from the same class of Ming Chuan College (junior program). These subjects were about one year younger than the subjects in group A and had studied English for five years. Students from both groups were taking College English courses at the time of the study. 
These two groups were not designed as experimental group and control group. Both group A and B were given exactly the same treatment. The subjects were separated into two groups because these two groups of students have very different educational experiences. Group A consisted of freshman students from regular colleges. They had studied English for one more year than group B students. More importantly, these students had passed the highly competitive College Entrance Exam eight months prior to this study. English was one of the most important test subjects in the exam. Group B students did not go to high school. They were in a five-year junior college program in which students entered the program after they graduated from junior high school. Compared to the regular high school students at the same age level, junior college students had easier English textbooks, less homework, and fewer hours of classroom instruction. Since these students did not prepare themselves for the College Entrance Exam, their motivation for studying English was lower. English proficiency level, therefore, was generally lower for group B students.

\section{MATERIALS}

Two vocabulary lists were designed by the researcher. The first list, the learning list, contained 38 common nouns which eventually were presented to all the subjects to learn. The second list, the additional list, contained five common nouns which would not be given to the subjects to learn; the words in the additional list served as distractors in the vocabulary recall tests. Fifty vocabulary 
items, ranked from 20,000 through 23,000 in word frequency, were first chosen from The American Heritage Word Frequency Book. All the spellings of the chosen vocabulary basically followed general English orthographic rules. A selection process was then conducted to reduce the likelihood of subjects' previously knowing these vocabulary words. Five Chinese graduate students at Portland State University assisted in the word selection process. These students were asked to cross out all the words that they knew from the list of 50 words. Only 38 words, which students were not familiar with, were eventually selected for the learning list. Words in the additional list were common words taken randomly from the dictionary.

Each word from the learning list and its related material were printed on a board that measured $17 \times 23$ inches. The related material included the definition of the word, its Chinese translation, and one sample sentence with the target word in context. Definitions of the words were taken from Longman Dictionary of Contemporary English and Oxford Advanced Learner's Dictionary of Current English. The Chinese translation of words was from Wen Shin English-Chinese Dictionary of Contemporary English. For the convenience of the word presentation, the boards were divided into eight groups with three boards in the last set and five boards in the rest of the groups.

Two sets of multiple choice tests, written by the researcher following the format of related published vocabulary tests, served as test material for the immediate recall test and the long term recall test. Each test contained 43 test 
questions in cloze format. Subjects needed to choose a single correct word from five choices. The correct answers for 38 of the questions were from the learning list. To reduce the chance of guessing, the correct answers for the other five questions were from the additional list. Except for the correct answer for each question, all the other choices were taken from either the learning list or the additional list. Every word in the two lists appeared in the choices with approximately the same frequency.

\section{RESEARCH DESIGN AND PROCEDURES}

This study is a correlational study designed to test if there is a relationship between subjects' ability to apply graphophonic strategy in learning vocabulary and the success of their learning. Subjects' ability to use graphophonic knowledge in learning was defined by the number of correctly pronounced words and the length of time used to read them. Based on my assumption, the subjects who used the graphophonic strategy in learning would be able to pronounce the words more quickly and correctly after the learning session. On the other hand, subjects who did not use graphophonic strategy in learning would not be able to read the vocabulary as fast and as correctly as those who did use phonetic strategy. Subjects' vocabulary learning success was defined by the scores of their immediate and long term vocabulary tests after the learning session.

This study consisted of four major sessions: the vocabulary learning session, the oral reading session, the immediate vocabulary test session, and the long-term 
recall test session. The study was conducted on a small group basis with eight to twelve students in each group. People in the same group would learn words and take tests together.

\section{The Learning Session}

After the subjects had entered the test room, the test conductor first introduced herself and two helpers to the subjects to reduce the tension of the subjects. The subjects were also assured of the fact that their performance on this study would not affect the score of their English classes. After the subjects began to feel relaxed, they were informed of the process of the learning session, which is explained below.

Subjects were asked to learn the meaning of words presented on the boards with their own strategies. Boards of the same set were presented one by one for thirty seconds each; then all these five boards were presented again for ten seconds each before the next set of boards was displayed. All the board sets were presented in the same manner one after another. After the above processes were completed, the researcher presented each board in a random order for five seconds each. With this learning session, students saw each word three times: 30 seconds, 10 seconds, and 5 seconds in each time.

\section{The Oral Reading Session}

This session was designed to determine the extent to which each student was able to apply a graphophonic strategy in learning words. The performance on 
students' oral reading of words from the learning list was used as a measure of how students learn these words. Each subject was given a tape recorder and a vocabulary list containing all the words presented in the learning session. Then subjects were separated and asked to read the words into their tape recorder. The purpose for separating one subject from another was to prevent the noise distraction made by other people. Each room to which subjects were assigned had a helper to assist the recording process.

Right after the oral reading session, the subjects were given a Chinese article to read. The article was about the experience of going to barber shops in old times. The article, written in a humorous tone, was chosen to help subjects relax after the heavy learning session. This reading exercise was also designed as a distractor so there would be five minutes' lapse before subjects took the shortterm recall test. After the Chinese reading exercise, each student was given a test containing questions about the vocabulary items they had just learned.

\section{The Vocabulary Tests}

After the Chinese reading exercise, subjects received a vocabulary test of 43 multiple-choice questions. They were given a maximum of 35 minutes to complete the test. However, most subjects completed all the questions in 25 minutes.

It was planned that the subjects would take another similar test on the vocabulary items they had learned two weeks later. Subjects of group A, following the schedule, took the second test 14 days after the initial test. However, due to 
scheduling problems, group B subjects took the second test only nine days after the initial test. Since the major purpose of the this study was not to compare the performance of the two groups, treating the groups differently should not interfere with the experimental results. Care must be taken not to compare the long term test scores between the two groups in evaluating the results.

\section{SCORING THE ORAL READING PERFORMANCE}

The ability of a subject to use graphophonic strategy in learning words was measured first by the accuracy of oral reading of the list of previously learned words. The score on the oral reading session was calculated based on the number of words pronounced correctly. Each correct pronunciation was counted as one point. However, since none of the subjects was a native speaker of English, the definition of "correct pronunciation" in this study was not too strict. Minor problems on stress level, Chinese accent, and using known words as pronunciation guides were not counted as errors. The following paragraphs will explain these scoring criteria in detail.

\section{$\underline{\text { Stress Pattern }}$}

First of all, stress pattern was not a concern in scoring. The underlying rationale was that insufficient knowledge of English stress patterns would not inhibit the use of phonetic strategy in learning words. For example, the person who stresses the first syllable of the word narcotic could still learn this word phonetically as [nárkatlk] without knowing the correct stress pattern. Note that 
vowels may change their pattern phonetically because of the stress level; thus the presumed "correct readings" were changed accordingly. For example, the vowe1 between $\mathrm{s}$ and $\mathrm{g}$ in the word sagacity should be schwa $[\theta]$ phonetically; however, if stressed, this vowel should be pronounced as [æ] by regular graphophonic rules. Similarly, the vowel between $\mathrm{g}$ and $\mathrm{c}$ would turn into schwa if not stressed. As a result, all the following pronunciations were counted as correct : [sǽgasati], [səgás tI], and [sægasÍtI].

\section{Chinese Accent}

Since all of the subjects were Chinese students from Taiwan, mistakes which may be caused by a Chinese accent were not counted as mistakes. Such pronunciation includes:

1. lax vowels pronounced as tense vowels: lax vowel [I] pronounced as [i] in cinch, grit, frolic, oblivion, and trinket.

2. [e] and [æ] pronounced as $[\epsilon]$ : [e] sound in gaze and cranium along with the [æ] sound in havoc, parody, rapture, gallantry, and magistrate pronounced as $[\varepsilon]$.

3. [ $\Lambda$ pronounced as [a]: the vowels in grudge, scuffle, and bluff pronounced as [a]

\section{Using Known Words as Pronunciation Guides}

As done in the study of Baron and Treiman (1980), the pronunciation of nonsense words was counted as correct if they were read by analogy with either 
the regular word or an exception word. The study in this thesis also followed the same principle. The underlying theory was that the ability to use graphophonic strategy included the ability to pronounce new words by using the phonetic knowledge of known words. For example, to pronounce the word sand, a person can use the words land or hand as models, thus pronouncing the word [sænd]. However, some target words are open to several possible pronunciations. For example, the target word rind should be pronounced as [raInd] according to words like find, bind, kind, and mind. However, if subjects treated rind as the structure of $\mathrm{r}+$ in + (consonant), they would use $\underline{\text { ring }}$ and $\underline{\text { rink }}$ as models, pronouncing rind as [rInd]. Even if they were to use an exceptional word, such as wind (puff of air) as their guide, students would pronounce the vowel in rind as [I]. The regular graphophonic rules still follow for the sound of [I] for the letter "i" in rind, even though this is not the correct pronunciation. Thus in the above situation, both pronunciations, [I] or [aI] were counted as correct.

A word generally was counted as incorrect when any of the vowels and consonants were misread (except for errors caused by reasons mentioned above), or when segments were added or deleted. The following list provides some examples of oral reading counted as incorrect.

havoc as [hævas] (mispronunciation of a consonant) nodule as [nadl] ([ju] sound omitted) impetus as [Impantæs] ([n] sound added)

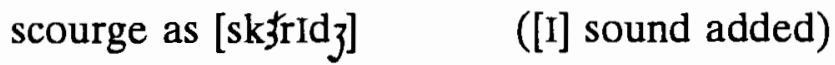


truant as [trant] $\quad([\mathrm{u}]$ sound omitted $)$

In addition to the researcher, a second rater (native American English speaker) helped in the scoring process. Twenty percent of the data was compared; the inter-rater reliability was 0.90 .

\section{ESTIMATING THE ORAL READING TIME}

The speed with which students read the words on the vocabulary list in the oral reading session provided another measure of the extent to which they were able to use a graphophonic strategy to learn words. It was assumed that students who have applied graphophonic strategy in learning would be able to pronounce the target words without hesitation right after the learning session. Subjects who did not apply graphophonic strategy in learning may use visual shape or other ways to store the target words in memory; thus they may need more time figuring out how to pronounce the words after the learning session. Subjects' reading speed was measured in seconds with a stopwatch.

It was found that although instructions were given that subjects should not read the number in front of each word, six subjects read the list in the following way: "The first word is grudge, the second word is frolic...". The phrases the first word, the second word, etc, were read in Chinese. In this manner these students used extra time telling the redundant information. To solve this problem, two sets of data were collected. The first set of data kept the six subjects; their reading time was estimated by subtracting the estimated time used for reading the 
redundant information from the total reading time. Estimated time for reading redundant information ranged from 0.40 to 0.90 second per item as measured by a stopwatch. Thus the total estimated redundant time for reading ranged from 15.2 $(0.40 \times 38)$ seconds to $34.2(0.90 \times 38)$ seconds per person who read the extra information. The second set of data, serving as a reference, was derived by deleting the six subjects from any data set in which reading time was a variable.

\section{SUMMARY}

This study borrowed an idea from Baron and Treiman's study (1983) that the ability to read an unknown word indicates a person's ability to apply graphophonic strategy in reading words. This implied that subjects who could not read any word correctly, or needed a long time figuring out the pronunciation of a word right after they had learned it, must not have used graphophonic strategy in learning. Conversely, subjects who could pronounce all words correctly and quickly must have known the English graphophonic correspondences very well. This suggested that there should be a range of performances on the reading session for the subjects. What the research design expected was that the degree of success on the oral reading test ought to correspond to the degree to which a subject has available a phonetic strategy for learning and remembering English words. Note that subjects who did well on the oral test did not prove that they actually applied graphophonic strategy in their learning. However, these subjects surely have the ability to apply graphophonic strategy while the subjects who failed 
to orally read words did not.

This study was designed to find the relationship between subjects' graphophonic ability and their vocabulary learning success. Four sessions were involved: a learning session for subjects to learn words; an oral reading session to test subjects' graphophonic ability; an immediate recall test to measure their short term learning success; and a long term recall test to examine their learning achievement after 14 days interval. This study was done in the hope of finding a positive correlation between oral reading scores and recall test scores as well as a negative correlation between oral reading time and recall test scores. If the hypotheses are supported, we can conclude that the graphophonic strategy helps students learn words more efficiently. 


\section{CHAPTER IV}

\section{RESULTS}

In this chapter the statistical results of all the measures on both groups are reported. These include general statistics and simple regression analysis on the four variables being measured: oral reading score, oral reading time, short-term vocabulary recall test score, and long-term vocabulary recall test score.

\section{GENERAL STATISTICS}

The results of the oral reading performance for group $\mathrm{A}$ is reported in Table I. Because six of the group A subjects took some extra time reading redundant information, their oral reading time was estimated by subtracting the estimated time used for reading the redundant information from the total oral reading time. To reduce the chance of estimation error, a second set of data was derived by deleting the six subjects from any data set in which reading time was a variable. Since all the statistical results indicated only slight differences between the two data sets, only the information from the first data set (the one with estimated reading time for six subjects) was analyzed. The information of the second data set (without the six subjects in question) served as a reference. Information from the second data set was put into parenthesis in all the tables. 
out of 38 total points with a mean of 27.54 points. They spent an average of 102.66 seconds, ranging from 50 to 171 seconds, to read through the vocabulary list.

The results of the oral reading session for group B is reported in Table II. Group B students scored from 5 to 35 points in the oral reading session with a mean of 21.61 points. They spent an average of 98.40 seconds to read the same list. Compared to group A students, group B students scored significantly lower (5.93 out of 38 points) at 0.05 significance level under Z-test in the oral reading session; however, group B members seemed to spend a little less time (4.26 seconds), although not statistically significant, in reading the list.

\section{TABLE I}

RESULTS OF THE ORAL READING PERFORMANCE FOR GROUP A

\begin{tabular}{lccc}
\hline & Reading Score & \multicolumn{2}{c}{ Reading Time } \\
\hline \hline Mean & 27.54 & 102.66 & $(101.09)$ \\
Standard Deviation & 4.87 & 27.59 & $(27.05)$ \\
Median & 28.00 & 102.00 & $(101.00)$ \\
Range & $10-36$ & $50-171$ & $(50-161)$ \\
\hline
\end{tabular}


TABLE II

RESULTS OF THE ORAL READING PERFORMANCE FOR GROUP B

\begin{tabular}{lcc}
\hline & Reading Score & Reading Time \\
\hline \hline Mean & 21.61 & 98.40 \\
Standard Deviation & 6.39 & 30.35 \\
Median & 21.00 & 93.00 \\
Range & $5-35$ & $50-200$ \\
\hline
\end{tabular}

The vocabulary test scores for group A is reported on Table III. Group A showed an average of 26.68 points out of 43 points on the short-term vocabulary recall test. On the second vocabulary test (the long-term vocabulary test), 14 days after the first one, the test scores dropped to an average of 15.98 points.

TABLE III

RESULTS OF VOCABULARY TESTS FOR GROUP A

\begin{tabular}{lcc}
\hline & Short Term Test & Long Term Test \\
\hline \hline Mean & 26.68 & 15.98 \\
Standard Deviation & 6.59 & 7.62 \\
Median & 27.00 & 14.00 \\
Range & $10-36$ & $4-33$ \\
\hline
\end{tabular}

As reported in Table IV, group B showed an average of 21.65 points on the short-term vocabulary recall test. On the long-term vocabulary recall test, nine 
days after the short term test, the average score dropped to 16.02 points.

Concerning the results of the short-term test, group A averaged significantly higher (5.03 out of 43 points) than group B at 0.05 significance level. Notice that the two groups did not take the long-term recall test under the same condition. (Group A waited five more days for the second test.) Thus the long term vocabulary recall test scores for the two groups should not be compared.

\section{TABLE IV}

\section{RESULTS OF VOCABULARY TESTS FOR GROUP B}

\begin{tabular}{lcc}
\hline & Short Term Test & Long Term Test \\
\hline \hline Mean & 21.65 & 16.02 \\
Standard Deviation & 6.08 & 6.01 \\
Median & 21.00 & 15.00 \\
Range & $9-34$ & $6-29$ \\
\hline
\end{tabular}

\section{RELATIONSHIP BETWEEN ORAL READING SCORES AND SHORT-TERM VOCABULARY TEST SCORES}

The Pearson product-moment correlation coefficient was used to measure the relationship between subjects' short-term vocabulary test scores and their reading scores. Both group A and group B students demonstrated a significant positive correlation between the oral reading scores and short-term vocabulary test scores at .05 significance level (one-tailed). As shown in Table V, group A had a correlation coefficient of 0.51 while group B had a coefficient of 0.53 . The 
squared value of $r, r=0.26$ and 0.28 , showed that the variation in reading scores accounted for about 26 and 28 percent of the variation among short term test scores for group A and group B, respectively. Both groups showed an upward trend on the scatterplot with reading scores on the $\mathrm{X}$-axes and short term vocabulary test scores on the Y-axes. (See Figure 1 and Figure 2). This upward trend demonstrated a positive correlation between the two measurements. The first hypothesis was supported by the results of both group A and group B.

\section{TABLE V}

CORRELATION BETWEEN ORAL READING SCORES AND SHORT-TERM VOCABULARY TEST SCORES

\begin{tabular}{lcc}
\hline & Group A & Group B \\
\hline \hline Correlation coefficient $(r)$ & $0.51^{*}$ & $0.53^{*}$ \\
$\mathrm{r}^{2}$ & 0.26 & 0.28 \\
Slope $(b)$ & 0.69 & 0.51 \\
Intercept $(a)$ & 7.80 & 10.72 \\
\hline
\end{tabular}

Note: ${ }^{*}=$ significant results at .05 significance level

\section{RELATIONSHIP BETWEEN ORAL READING SCORES AND LONG-TERM VOCABULARY TEST SCORES}

Both group A and group B students demonstrated a significant positive correlation between the oral reading scores and short-term vocabulary test scores at .05 significance level (one-tailed). As shown in Table VI, group A had a correlation coefficient of 0.70 while group B had a coefficient of 0.54 . The 


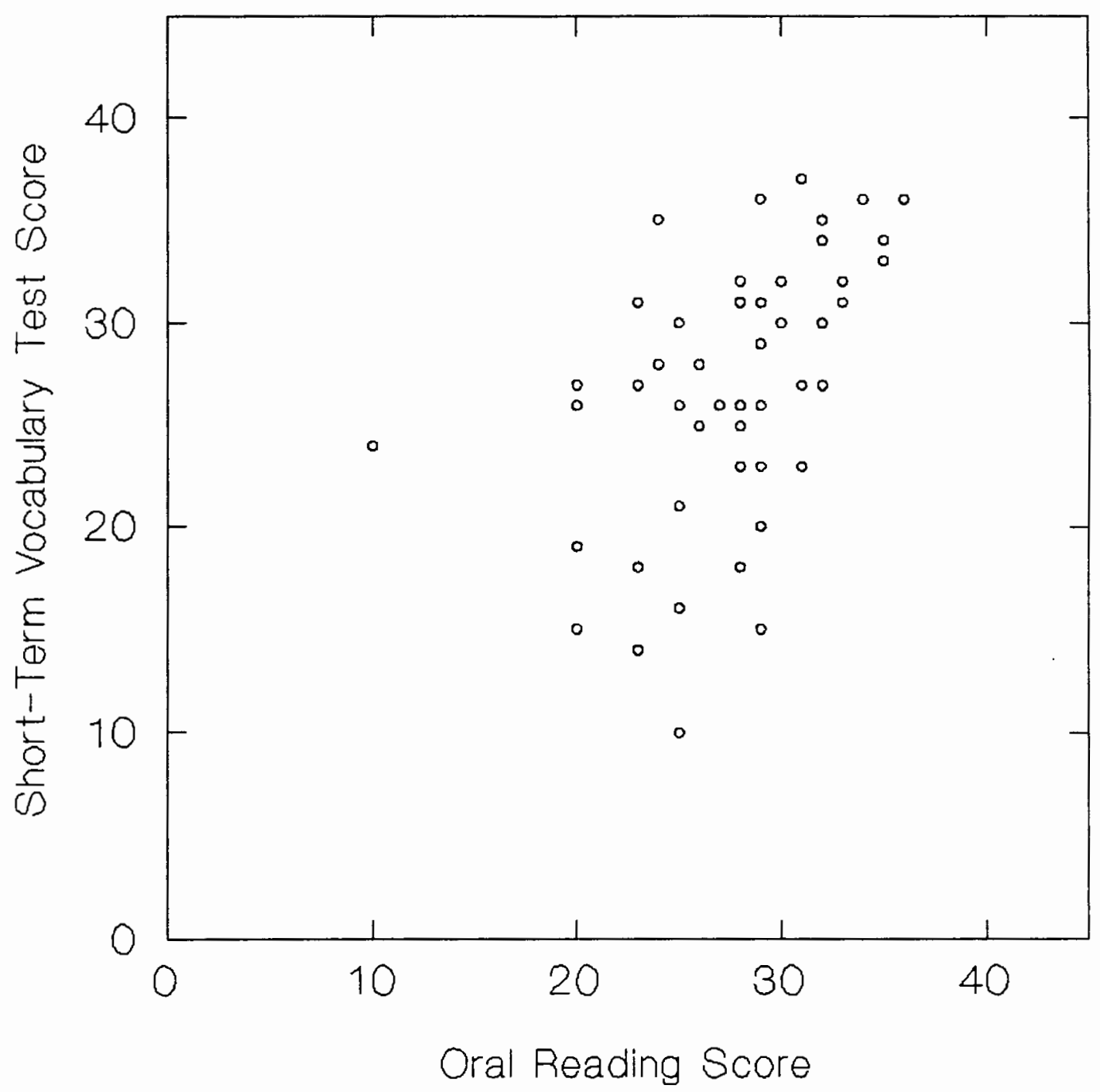

Figure 1. Relationship between oral reading scores and short-term vocabulary test scores for Group A. 


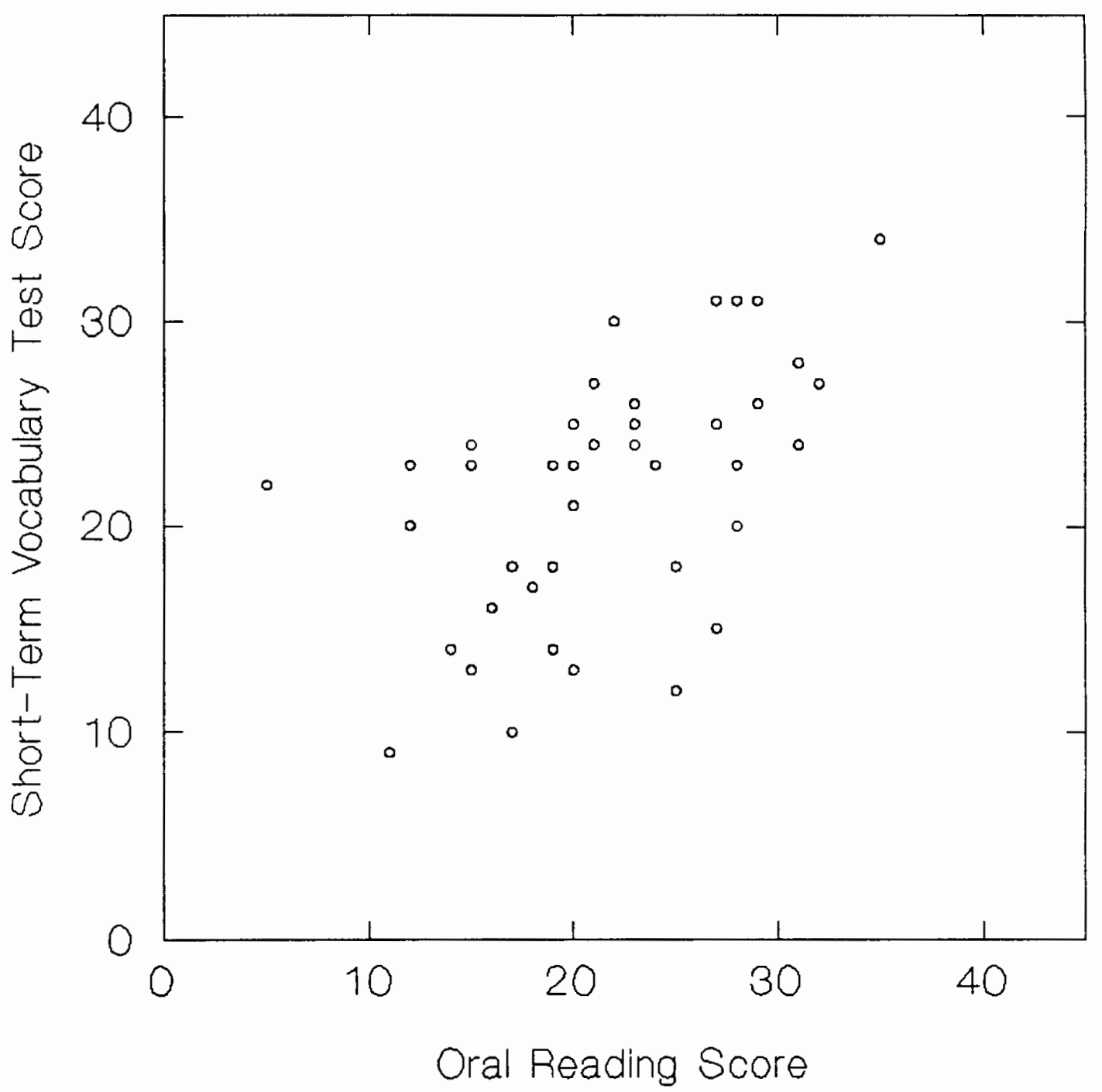

Figure 2. Relationship between oral reading scores and short-term vocabulary test scores for Group B. 
variation in reading scores accounted for 49 percent of the variation among longterm test scores for group A, but it accounted for only 29 percent of the variation among long-term scores for group B. Both groups showed an upward trend on the scatterplot of reading scores and short-term test scores, demonstrating a positive correlation between the two measurements. (See Figure 3 and Figure 4.) Thus the second hypothesis was supported by the results of both groups, especially by the high correlation results of group A. Note that for group A, the correlation coefficient between long term test scores and oral reading scores was about 0.2 point higher (in a scale from 0 to 1 ) than the correlation between the short-term test scores and the oral reading scores. For group B, this difference between the two correlations was only about 0.01 point.

\section{TABLE VI}

CORRELATION BETWEEN ORAL READING SCORES AND LONG-TERM VOCABULARY TEST SCORES

\begin{tabular}{lcc}
\hline & Group A & Group B \\
\hline \hline Correlation coefficient $(\mathrm{r})$ & $0.70^{*}$ & $0.54^{*}$ \\
$\mathrm{r}^{2}$ & 0.49 & 0.29 \\
Slope $(b)$ & 1.10 & 0.51 \\
Intercept $(a)$ & -14.13 & 5.04 \\
\hline
\end{tabular}

Note: ${ }^{*}=$ significant results at .05 significance level 


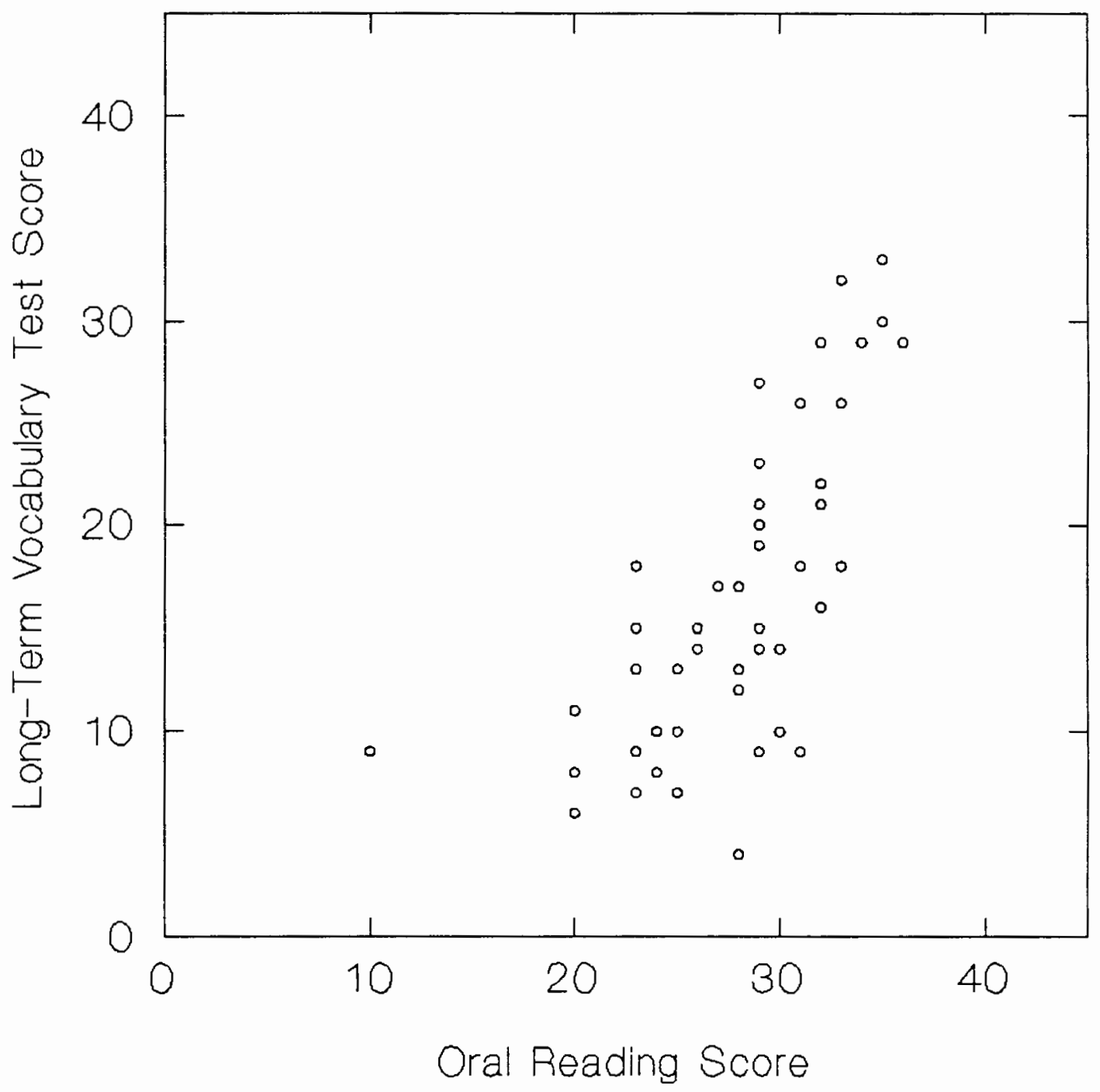

Figure 3. Relationship between oral reading scores and longterm vocabulary test scores for Group A. 


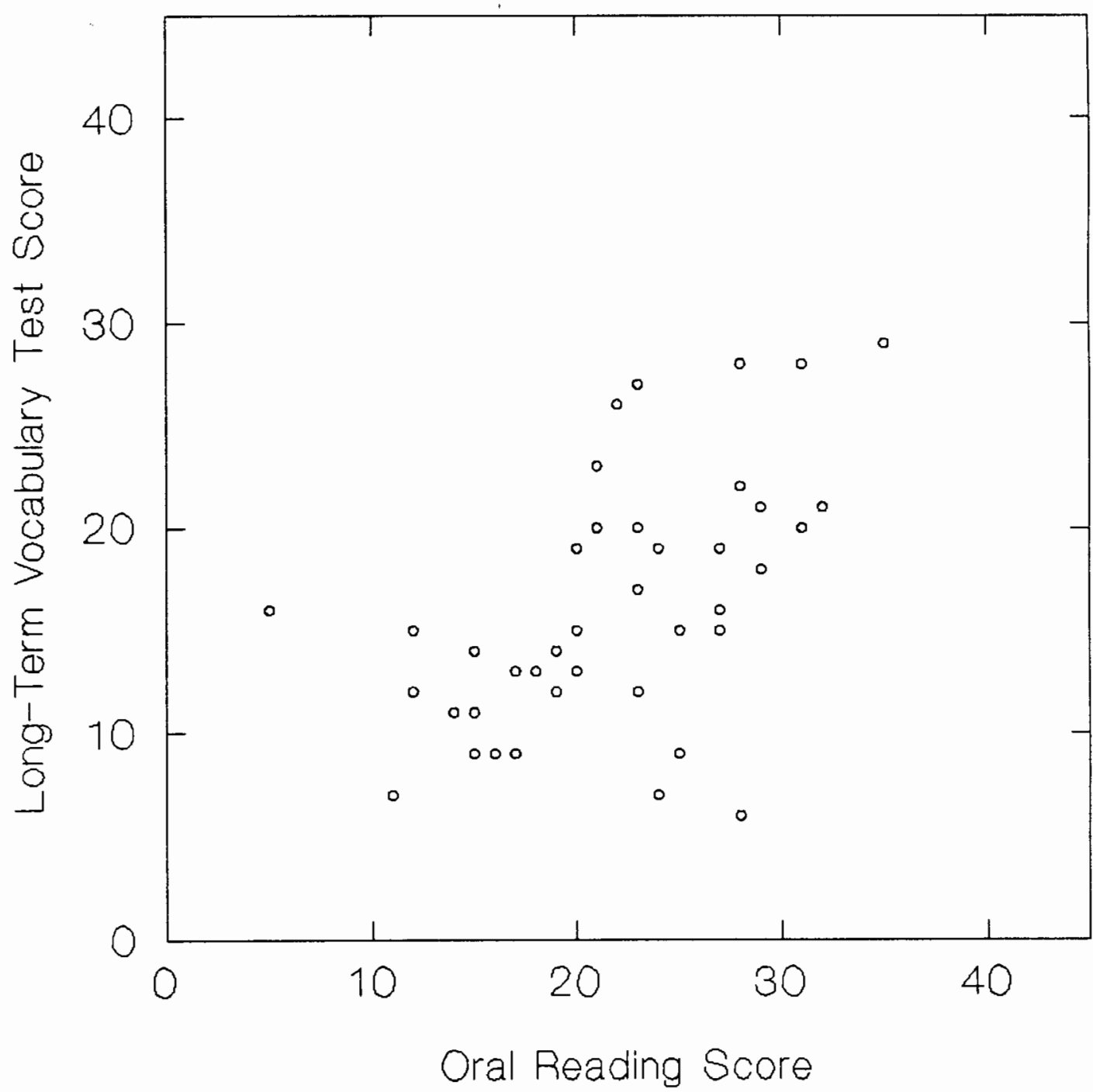

Figure 4. Relationship between oral reading scores and longterm vocabulary test scores for Group B. 


\section{RELATIONSHIP BETWEEN ORAL READING TIME AND SHORT-TERM VOCABULARY TEST SCORES}

The Pearson product-moment correlation coefficient was used to measure the relationship between subjects' short-term vocabulary test scores and their reading time. Group A students demonstrated a significant negative correlation between the oral reading time and short-term vocabulary test scores at .05 significance level (one-tailed). For group B subjects, however, the correlation between the two measurements was not significant. As shown in Table VII, group A had a correlation coefficient of -0.56 while group B showed only a very low correlation of -0.03 . The variation in reading time accounted for 32 percent of the variation among short-term vocabulary test scores for group A; but for group B it accounted for only 0.1 percent of the variation. As a result, a clear downward trend can be seen from the scatterplot of group A concerning reading time and short-term vocabulary test scores (see Figure 5). The scatterplot for group B, on the other hand, did not show any trend because of the weak relationship between the two measurements. (see Figure 6). Thus the results for group A supported the hypothesis $2 \mathrm{a}$ (see p.7) of this study; but this hypothesis was not supported by the results for group B. 
TABLE VII

CORRELATION BETWEEN ORAL READING TIME AND

SHORT-TERM VOCABULARY TEST SCORES

\begin{tabular}{lccc}
\hline & \multicolumn{2}{c}{ Group A } & Group B \\
\hline \hline Correlation coefficient $(\mathrm{r})$ & $-0.56^{*}$ & $\left(-0.53^{*}\right)$ & -0.030 \\
$\mathrm{r}^{2}$ & 0.32 & $(0.28)$ & 0.001 \\
Slope $(b)$ & -0.13 & $(-0.13)$ & -0.006 \\
Intercept $(a)$ & 40.45 & $(40.12)$ & 22.253 \\
\hline
\end{tabular}

Note: ${ }^{*}=$ significant results at .05 significance level 


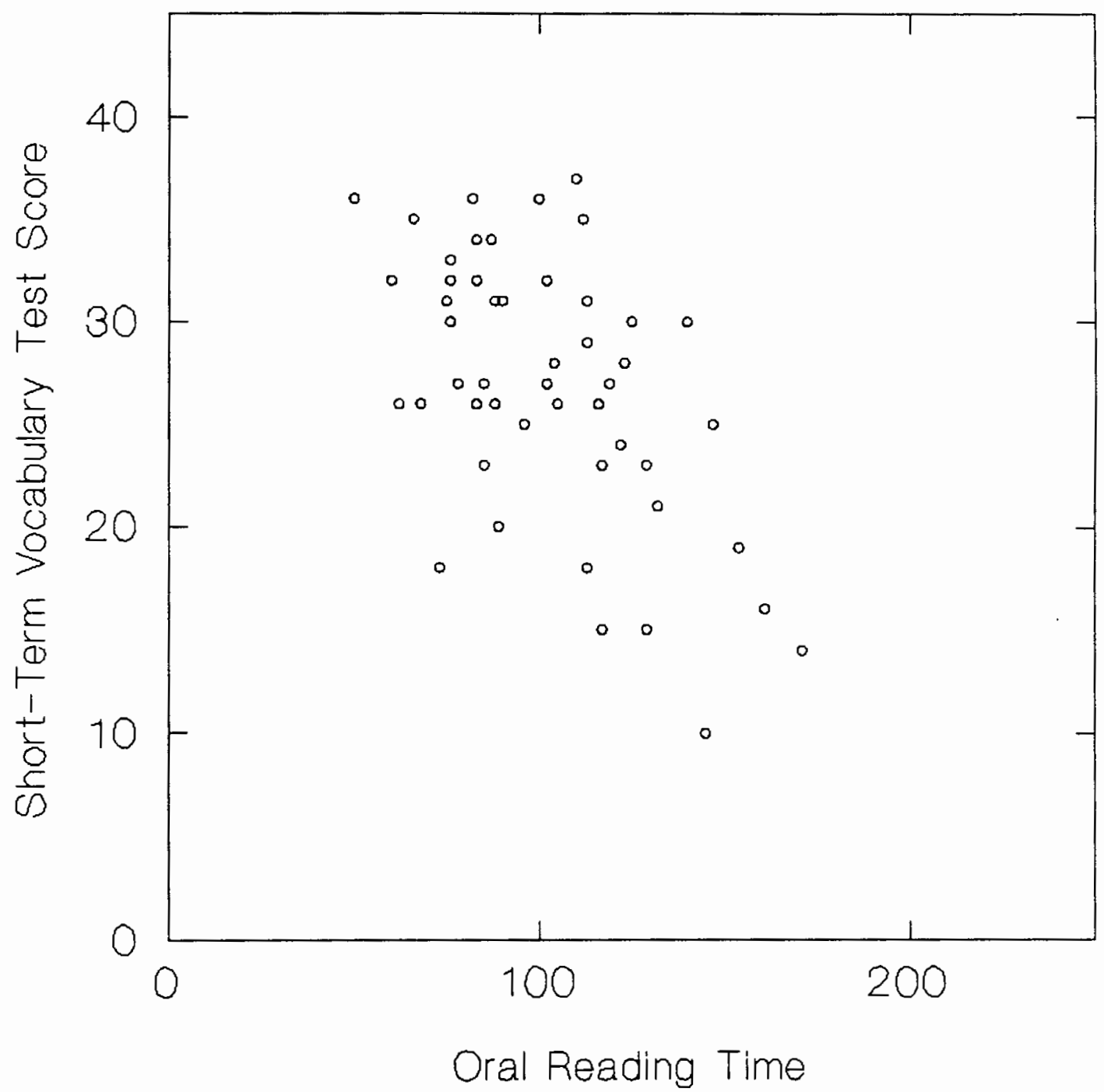

Figure 5. Relationship between oral reading time and short-term vocabulary test scores for Group A. 


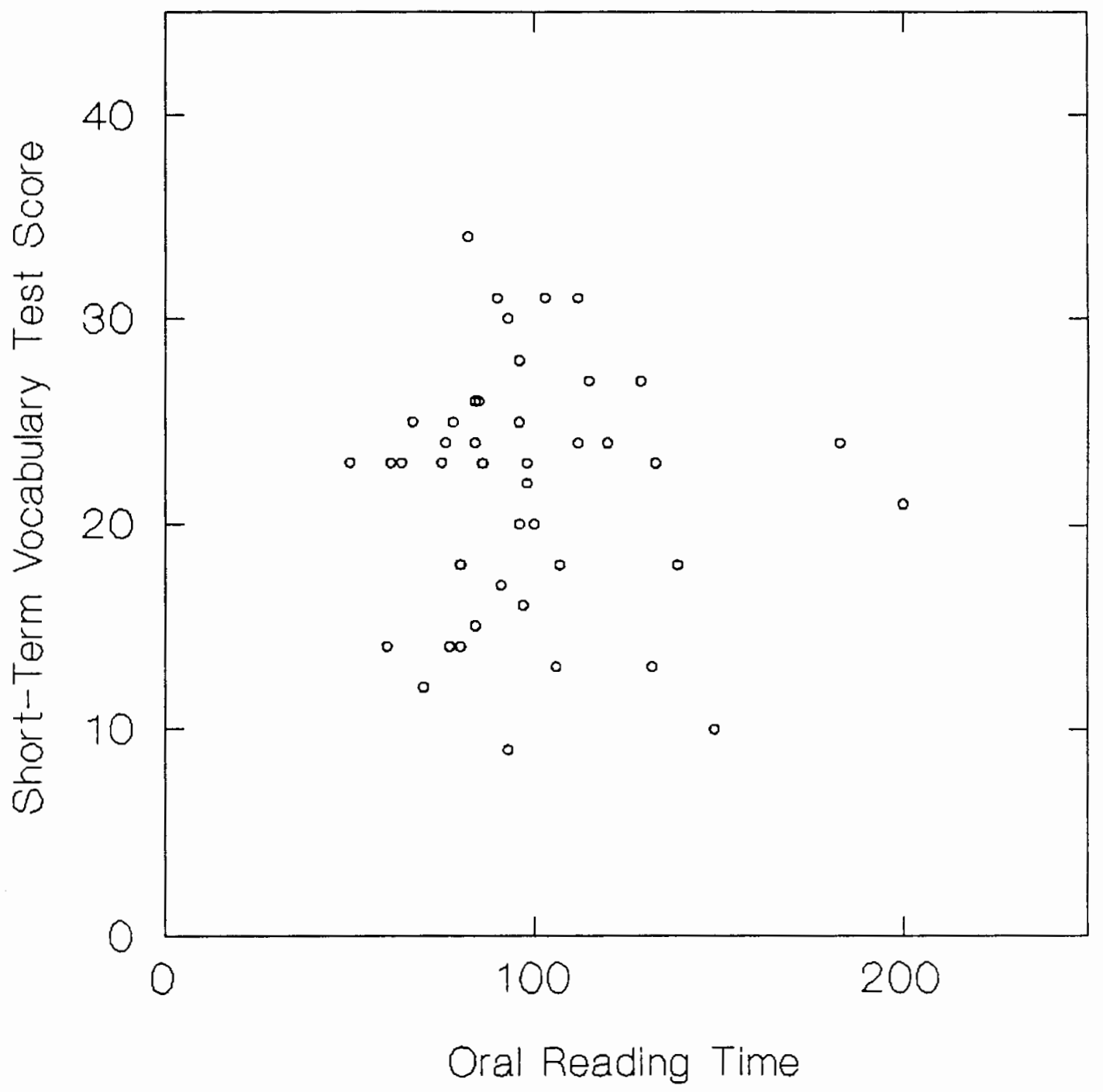

Figure 6. Relationship between oral reading time and short-term vocabulary test scores for Group B. 


\section{RELATIONSHIP BETWEEN ORAL READING TIME AND LONG-TERM VOCABULARY TEST SCORES}

Group A students demonstrated a significant negative correlation between the oral reading time and long-term vocabulary test scores at .05 significance level (one-tailed). There was no significant correlation between the two measures for group B. As shown in Table VIII, group A had a correlation coefficient of -0.49 while group B had a coefficient of only -0.030 . Notice that for group A, the correlation between vocabulary test scores and reading time dropped a little, but not much, from short-term test to long term test ( 0.07 point). The correlation between test scores and oral reading time stayed the same for group B. Graphically, there was a downward trend on the scatterplot of reading time and long-term test scores for group A, demonstrating a negative correlation between the two measurements (see Figure 7). There was no obvious trend on the scatterplot for group B because of the weak correlation (see Figure 8). Thus the last hypothesis, hypothesis $2 \mathrm{~b}$ (see p.7), was supported by the result of group A, but was not supported by the result of group B. 
TABLE VIII

CORRELATION BETWEEN ORAL READING TIME AND

LONG-TERM VOCABULARY TEST SCORES

\begin{tabular}{lccc}
\hline & \multicolumn{2}{c}{ Group A } & Group B \\
\hline \hline Correlation coefficient $(\mathrm{r})$ & $-0.49^{*}$ & $\left(-0.48^{*}\right)$ & -0.030 \\
$\mathrm{r}^{2}$ & 0.24 & $(0.23)$ & 0.001 \\
Slope $(b)$ & -0.14 & $(-0.14)$ & -0.006 \\
Intercept $(a)$ & 29.84 & $(30.78)$ & 16.605 \\
\hline
\end{tabular}

Note: ${ }^{*}=$ significant results at .05 significance level 


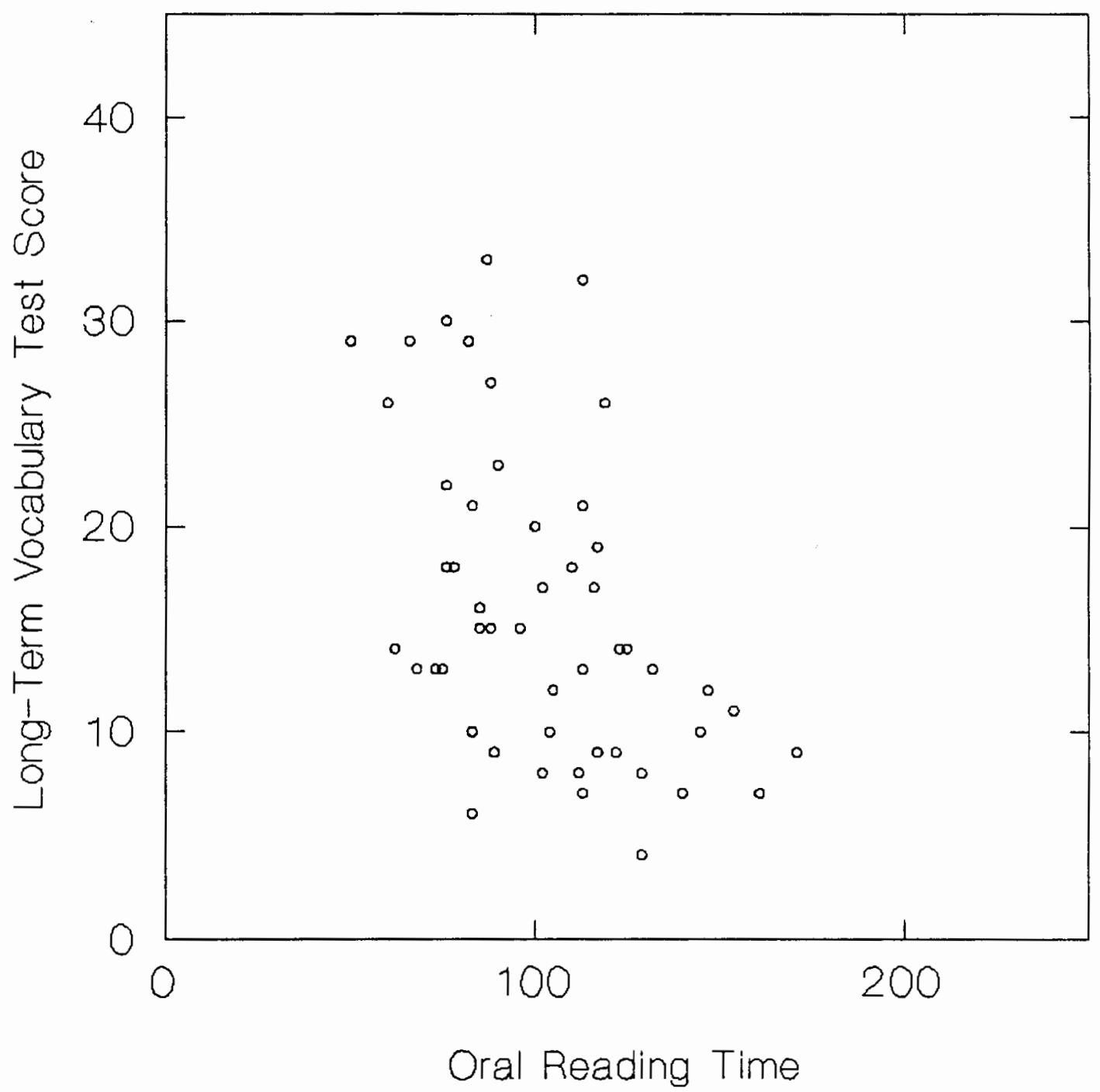

Figure 7. Relationship between oral reading time and longterm vocabulary test scores for group A. 


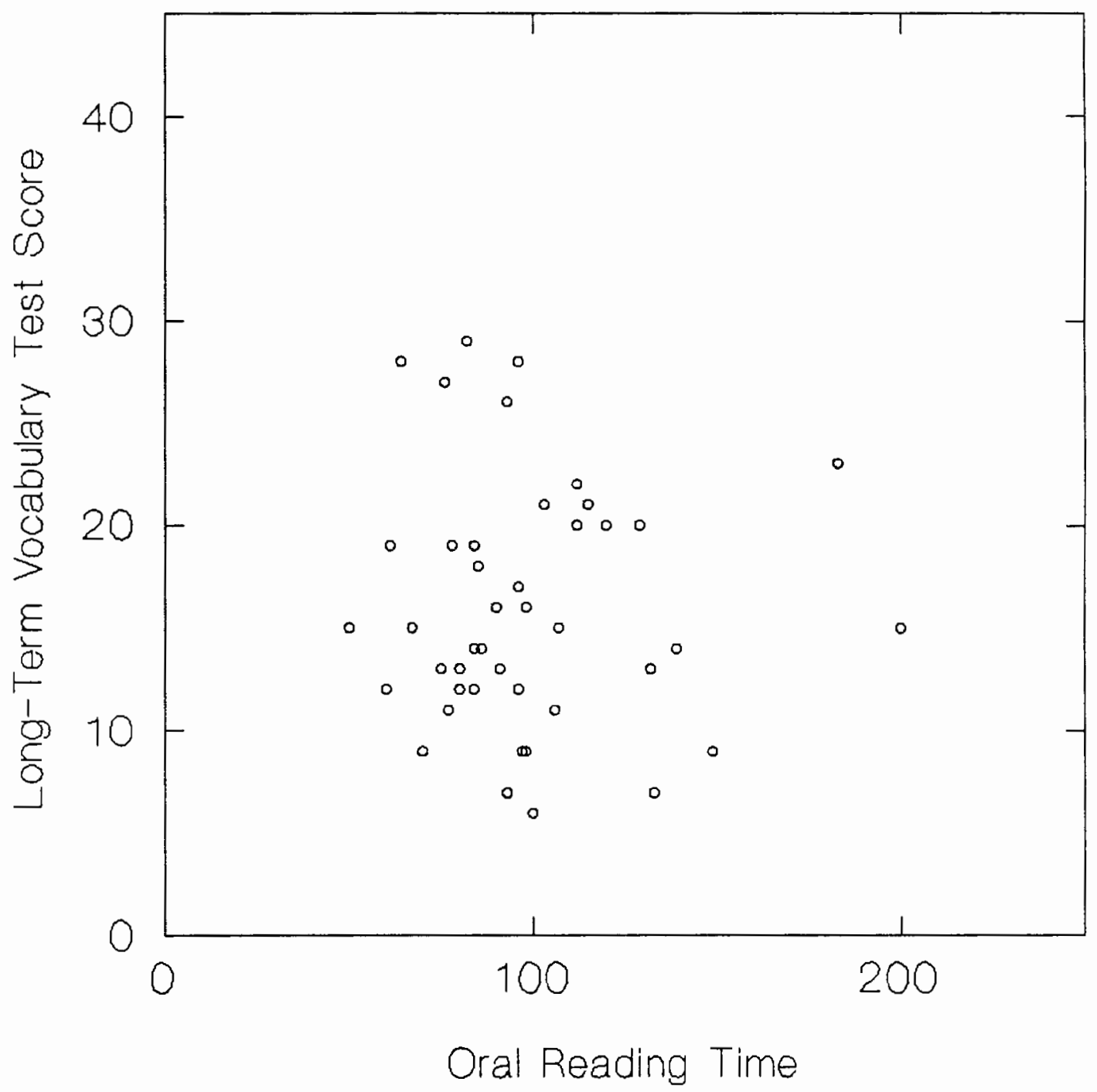

Figure 8. Relationship between oral reading time and longterm vocabulary test scores for group B. 


\section{CHAPTER V}

\section{INTERPRETATION OF RESULTS}

This chapter interprets the statistical results of the different measurements being used in this study. The original hypotheses state that there will be significant positive correlations between oral reading scores and the two vocabulary recall test scores and that there will be significant negative correlations between oral reading time and the two vocabulary recall test scores. The results showed that the performance of group A yielded statistical results which supported all the hypotheses. Group B supported only hypotheses $1 \mathrm{a}$ and $1 \mathrm{~b}$. The other two results, corresponding to hypotheses $2 \mathrm{a}$ and $2 \mathrm{~b}$, although not statistically significant, at least followed the trend as predicted. Since the two groups are heterogeneous, between-group differences may not be meaningful; but comparisons between the groups generated some interesting speculations. It could be speculated that the correlation between graphophonic ability and learning success would be greater for learners with higher graphophonic maturity. Nevertheless, the statistical results mostly supported the general hypothesis that the ability to apply graphophonic strategy in learning words correlated positively with the success of learning. 
INTERPRETATION OF THE CORRELATION BETWEEN ORAL READING SCORES AND SHORT-TERM VOCABULARY TEST SCORES

The statistical results of both groups supported the hypothesis that subjects' oral reading scores correlated positively with their short-term vocabulary test scores. In other words, there was a significant positive relationship between subjects' ability to read untaught words correctly and their short-term vocabulary learning achievement. That is, the better a subject could read new words without instructions or the help of phonetic symbols, the more likely he or she would be to learn words successfully in the short run. Since subjects' ability to read unknown words indicated their ability to use graphophonic strategy in learning, the above results could mean that students who were able to apply graphophonic strategy in learning words are more likely to succeed in learning English vocabulary, at least for the short term.

As predicted, an upward trend can be seen on the plots of the relationship between reading scores and short-term vocabulary test scores (See Figure 1 and Figure 2). Nearly all of the samples of group A (except for the one with the lowest reading score) fit with the trend nicely. A similar situation occurred with group B. The smooth distribution again confirmed the hypothesis of this study. However, each group had one "exception" case. These two exception cases scored extremely low on the reading scores compared to other group members, but their short-term vocabulary test scores were about average among other subjects of their groups. Such low oral reading scores (10 and 5 points out of 38 total points) 
indicated that the subjects in question knew very little about graphophonic rules. However, their moderate short-term test scores indicated that other strategies, like visual whole-word recognition or other strategies which involved no graphophonic skills, could be effective for some students in the short-term vocabulary learning.

\section{INTERPRETATION OF THE CORRELATION BETWEEN ORAL READING SCORES AND LONG-TERM VOCABULARY TEST SCORES}

Again, the hypothesis that subjects' oral reading scores correlated positively with the long-term vocabulary test scores was supported by the results of both groups. This indicated that the greater the subjects' knowledge of graphophonic correspondences, the more likely they would be to remember a word several days after the learning. Since the long-term test posed a different task than the shortterm test, some interesting phenomena could be observed. The short-term vocabulary test measured initial learning and immediate retention, while the longterm test measured extended memory retention. The significant positive correlation between short-term test scores and reading scores indicated that graphophonic knowledge could promote better learning. The significant positive correlation between long term vocabulary test scores and reading scores showed that graphophonic strategy also could help vocabulary retention in the long run. In other words, graphophonic strategy helps learners not only in short-term learning, but also in long-term memory retention.

Notice that for group A, this correlation coefficient was larger than the correlation coefficient between reading scores and short-term test scores by almost 
0.2 point $(0.70-0.51=0.19)$. The stronger correlation between the reading scores and long-term test scores indicated that while a graphophonic strategy aided learning, it aided long-term retention even more; thus the effectiveness of graphophonic knowledge in long-term vocabulary retention is even more strongly supported than its effectiveness in initial learning. This result also suggested that some students who used other strategies in learning might be able to memorize words as well as the students using graphophonic strategy in the short run, but they would forget the words sooner. Figure 1 and Figure 3 supported this point. Three of the five group A subjects who ranked lowest on the reading score (including the lowest one mentioned earlier) were able to score moderately (24, 26, and 27 points) in the short-term vocabulary test; however, their-long term test scores ranked among the lowest. Since subjects who ranked low would not know much about graphophonic rules, they must have used other strategies during the vocabulary learning session. The fact that they could manage to remember words in the short term but not in the long term implied that their strategies of learning, probably by identifying visual shape or by rote-memorizing the constituents of a word, were not effective in the long run. Thus based on the statistical results of group A, using graphophonic strategy for learning vocabulary was superior to using other strategies in retaining the words in the long-term memory.

For group B, the difference between the above mentioned two correlations was much less $(0.54-0.53=0.01)$. One possible explanation for this was that group B students took the second test nine days after the first one while group A 
students took the same test fourteen days after the initial test. The extra five days (55 percent more time) could broaden the difference between subjects' short-term versus long-term performance; the superiority of using graphophonic learning strategies thus could be more clearly revealed five days later. In fact, the additional five days seems to have made a lot of difference. Without the additional five days, the average score on the long-term test for group B was higher than that of group A. Since group A subjects scored significantly higher than group B in the short-term test, one would assume that group A should have scored higher than group B in the long-term test, if both groups had taken the second test after the same time interval. The fact that group B was superior to group $A$ in the long-term test but scored much lower than group $A$ in the shortterm test suggested that the extra five days could have changed the distribution of long-term test scores. If group B had taken the second test under the same condition as group A, the difference between the two correlation coefficients mentioned above might have been greater.

Another possible explanation is that students need to achieve a certain level of graphophonic maturity before they can take full advantage of the graphophonic strategy. Group A subjects apparently were superior on graphophonic skills because of the higher average reading score. The oral reading results indicated that group A scored significantly higher than group B students: 90 percent (45 out of 50 cases) of group A subjects scored higher than the average score of group B. Thus most of the group B subjects who scored relatively high 
(highest third) among their group members would only score moderately or even moderately low among group A subjects. In other words, the high-scorers of group B could not actually be considered superior to group A in knowing the graphophonic correspondences. These "relatively better" group B subjects, compared to the members in group A who scored high on oral reading, might only possess partial knowledge of the graphophonic rules. The rest of the group B members were even worse in graphophonic maturity. This partial knowledge may not help them retain words in memory over a longer period of time. For group B, although there was a positive correlation between the long-term vocabulary test scores and oral reading scores, the correlation could not be as high as that of group A.

\section{INTERPRETATION OF THE CORRELATION BETWEEN ORAL READING TIME AND SHORT-TERM VOCABULARY TEST SCORES}

The second hypothesis in this study proposed that subjects who use graphophonic strategy in learning words will be able to read the learned words faster than those who do not use graphophonic strategies; hence the time used for reading the learning list following the learning session could be an indicator of the extent students used graphophonic strategy in learning. Therefore, if graphophonic strategy is effective, there should be a significant negative relationship between oral reading time and short-term vocabulary test scores. The statistical results of group A supported this hypothesis by showing a significant negative correlation coefficient of -0.56 . As in the previous correlation between 
oral reading scores and short-term vocabulary test scores, this result confirmed the notion that there was a strong relationship between the use of graphophonic strategy (measured by the amount of time used to read the list) and the effectiveness of short-term learning.

The statistical analysis of group B showed a different result. The negative correlation $(-0.03)$ followed the prediction that the faster a student could read the list, the higher his or her score would be on the short-term test. However, this correlation was not statistically significant, indicating that the relationship between the short-term vocabulary test scores and the reading time was low. This result should not overrule the general hypothesis about the relationship between the use of graphophonic strategy and the success of learning, since group A and group B subjects took different approaches when they confronted words that they could not pronounce. Details of this observation will be discussed later.

\section{INTERPRETATION OF THE CORRELATION BETWEEN ORAL READING TIME AND LONG-TERM VOCABULARY TEST SCORES}

Again, the statistical result of group A supported the hypothesis that there was a significant negative correlation between reading time and long-term vocabulary test scores. This result again confirmed the original hypothesis that the more a student can apply graphophonic rules in learning words (measured by the time used to read the learning list), the better he or she can remember the words 
in the long run. However, as in the previous case, the result of group B failed to confirm the predicted relation between the long-term test score and oral reading time.

\section{GROUP DIFFERENCES BETWEEN GROUP A AND GROUP B}

All the four hypotheses were supported by the statistical results of group A; but for group $\mathrm{B}$, hypotheses $2 \mathrm{a}$ and $2 \mathrm{~b}$ (on the relationship between reading time and vocabulary test scores) were not statistically confirmed. This unexpected discrepancy probably was caused by the different strategies that the two groups followed in approaching the oral reading task.

Based on the researcher's observation, group A subjects usually took more time trying to figure out the correct pronunciation of an unknown word while group B subjects quickly passed over a word they did not know how to pronounce. Statistical results also supported this observation. For group A, there was a significant negative correlation $(-0.46)$ between oral reading scores and oral reading time. This indicated that the better a student knew graphophonic correspondences, the faster he or she would read the list; the less the student knew the correspondences, the slower he or she would read the list. For group B members, however, the correlation between oral reading scores and reading time was only 0.006 . This indicated that there was no relationship between the students' graphophonic ability and their reading speed. Because group B subjects read the list in this unexpected manner, measuring the extent of graphophonic 
skill according to the time spent reading the vocabulary list was not successful. It could be speculated that group B subjects had not achieved a level of graphophonic proficiency that would allow them to apply the rules; thus they did not intend to spend time figuring out the pronunciation of unfamiliar words. Thus for subjects who were below a certain level of graphophonic maturity, reading time may not provide a valid quantitative measure of the degree of their skill.

Affective factors in oral language performance could also influence the validity of using reading time as a measure of graphophonic skill. Unlike group A, group B was composed of young female students. In the researcher's personal observation, these girls were not confident in their spoken English; their shyness also prevented them from speaking a foreign language in the presence of test conductors. When they were told that their voices would be recorded, they giggled and tried to persuade the test conductors to give up the recording process. When these girls did not know how to read a word, they obviously did not like to spend time figuring out the correct pronunciation in front of the tape recorder. As a result, their reading speed did not truly reflect their knowledge of graphophonic correspondences. Thus the low correlation for group B between reading time and vocabulary test scores did not necessarily show that there was no relationship between graphophonic ability and vocabulary learning success.

In fact, not only the correlation between oral reading time and vocabulary test scores showed group differences, but the overall results demonstrated that group A had stronger correlations in all the measures. Since group A members 
generally had better control of graphophonic skills than group B subjects did, it seems that there is a positive correlation between degree of graphophonic skill and the correlation between graphophonic skill and vocabulary learning success. In other words, students who have a greater control of graphophonic strategies will also demonstrate a higher correlation between graphophonic skills and vocabulary learning success. A possible explanation of this phenomenon could be that as the level of graphophonic skill dropped, subjects would need to rely more on the other strategies, such as holistic or visual recognition method, in the vocabulary learning tasks. Thus the correlation between the level of graphophonic skill and vocabulary learning success began to fall. It remains unknown how students with absolutely no graphophonic skill would perform on the vocabulary learning task. At least the available data in this study suggested that subjects who scored very low on the oral reading task could, at their best, score moderately on the short term vocabulary recall test; but they could not score among the highest. Besides, they could not maintain their moderate level in the long-term vocabulary test. All these observations, together with the statistical results mentioned earlier, suggest that graphophonic strategy remains a superior strategy in learning vocabulary.

\section{LIMITATIONS OF EXPERIMENTAL DESIGN}

Although statistical results showed that there was a significant positive relationship between graphophonic skill and vocabulary learning success, there was 
no proof to rule out the possibility that the relationship was caused by the superiority of overall skill at vocabulary learning. It is possible that some of the subjects who performed well on the oral reading task were globally better learners, who controlled all word-learning skills, including graphophonic strategy and all others. Their superior performance may not be the result of their superiority at one specific word learning skill, namely, graphophonic strategy, but a result of having all strategies available. Since this study did not measure whether the degree of graphophonic skill correlated with visual or holistic word recognition skills, there remains a possibility that graphophonic skill was not the sole factor in causing the significant correlations with learning success. However, even if this is true, a weaker conclusion could still be drawn from this study: learners who had available a graphophonic strategy, one of the overall vocabulary skills, were better than the ones who did not.

Also, as mentioned in previous chapters, this study measured the availability of a graphophonic strategy, not subjects' actual use of such a strategy. An assumption was made that if subjects had graphophonic skill, they would use it in the word-learning task. On the hypothetical situation, subjects who did not have any graphophonic skill (those who could not read any of the words in the learning list) must have used no graphophonic strategy in learning. However, the degree to which students with graphophonic skills actually used those skills could 
not be measured quantitatively in this experimental design. Further research should be designed to measure the extent of actual use of a graphophonic strategy.

\section{SUMMARY}

The extent to which Chinese subjects were able to use graphophonic knowledge in learning English vocabulary was measured in two ways: first by the number of words subjects could read correctly after the learning session; second by the time used to read these words. The hypothesis that there would be a positive correlation between the reading scores and the short-term vocabulary test scores was supported by the statistical results of both group A and group B. The hypothesis on the positive correlation between reading scores and long-term recall test scores was also supported by the results of both groups. However, the hypothesis that there would be a negative correlation between the reading time and short-term vocabulary test score was supported only by the results of group A. The same situation occurred with the hypothesis on the negative relationship between reading time and long-term vocabulary test scores. Because six out of eight correlations were significant, it can be concluded that there indeed is a positive relationship between the ability to use graphophonic strategy in learning words and the success of retaining the words in short-term and long-term memory. One possible reason for the inconsistency of results for the remaining two correlations is that the time used to read the learning list did not truly reflect 
group B's knowledge about graphophonic rules.

There also is a strong possibility that graphophonic strategy would demonstrate a greater effect in helping students remember words in the long run. After a two-week interval, the long-term vocabulary test scores for group A showed a greater correlation with the oral reading scores than the short-term vocabulary test scores did. This result suggested that although non-graphophonic strategies could help learning in the short run, these strategies could not compete with the use of graphophonic rules in the long run.

Finally, a certain level of graphophonic knowledge may be necessary before students can take advantage of the graphophonic strategy to the fullest extent. The average oral reading score for group B was much lower than group A, indicating the subjects of group B were inferior in their ability to use graphophonic knowledge. This incomplete knowledge, in turn, might reduce the effectiveness of using graphophonic rules and cause the majority of correlation results of group B to be lower than those of group A. However, it seemed that having an incomplete graphophonic knowledge was still better than having none at all, because even with group B, there was a significant positive relationship between reading score and vocabulary test scores. 


\section{CHAPTER VI}

\section{CONCLUSIONS AND RECOMMENDATIONS}

Currently, most vocabulary teaching in ESL and EFL courses is part of reading or speaking classes, where the vocabulary is introduced in the context of classroom material. Many teachers assume that by providing a definition, examples, and the pronunciation of a word to students, students can learn that word easily by themselves in the reading context. While this approach enhances learning by putting the word in the context of real use instead of in a made-up environment, it fails to provide students with strategies of learning and remembering words. For example, this contextual approach does not teach students whether they should learn a word by the shape or by its sound; nor does it tell students how to memorize a word they have just learned. By applying graphophonic strategy, native speakers of English can easily transfer a new word from the printed form to the spoken form; the sound of a word can be learned and memorized even though they have never heard it pronounced. Thus when a word appears a second time, either in the form they have previously experienced or in an alternative form, they can recognize it immediately. However, non-native speakers of English, if they are not familiar with the graphophonic correspondences, may not be able to learn a word easily in a form other than the one they have previously experienced. Because many EFL students encounter the 
situation of learning through reading, they may eventually learn many words in the written form only; and the pronunciation of these words may never be memorized by some of the students. Since one of the most important learning strategies is not available, overseas students may have difficulty learning and remembering English vocabulary items very efficiently.

The lack of knowledge of graphophonic correspondences for English is especially a problem for Chinese students, who are not familiar with alphabetic systems. The Written Chinese language is composed of logographic characters, each of which corresponds to a single word. The structure of each character and the composition of strokes do not provide much hint about the pronunciation of the word. Thus for Chinese students, character learning means copying down each character stroke by stroke and identifying it by its unique shape. Since there is no phonetic blending process involved in learning to read and spell, Chinese students generally do not analyze printed words phonetically when they begin to learn English. Instead, they tend to transfer their learning strategy from Chinese and learn English words through rote learning and visual identification. While this can be a perfect way for learning characters, it may not be very efficient for learning English words. The question then arises whether Chinese students can learn English words efficiently if they do not know how to pronounce those word; or, whether the knowledge of graphophonic correspondences will help Chinese students learn.

This thesis investigated the question of whether Chinese students could 
benefit from the knowledge of graphophonic correspondences to learn words. This research used a correlational study to test for a relationship between subjects' ability to use graphophonic skills in learning vocabulary and their learning success. If the relationship is statistically significant, the use of graphophonic strategy will be helpful in learning words. One of the underlying assumptions was that in order to apply graphophonic skill in learning vocabulary, one must be able to read an unknown word without instructions. The number of unknown words subjects could read thus indicated their ability to use graphophonic strategy in learning. Words printed on boards were presented to subjects, who were then asked to learn each word by their own strategies. Each word was presented along with its definition, its Chinese translation, and one sample sentence with the target word in context. However, no hint about the pronunciation was provided; in this way students who did not know graphophonic correspondences were not able to learn the word by its sound. After the learning session, students were asked to read a list of all the previously learned words into the tape recorder. The number of words they could read and the time spent in reading were used as indicators of subjects' ability to apply graphophonic strategy in learning vocabulary. That is, the more words they could read and the less time they spent in reading, the more proficient they were presumed to be in applying graphophonic rules. Subjects were also given vocabulary tests twice: immediately after the learning session and two weeks (or nine days for group B) after the learning session. The vocabulary test results served as measurements of subjects' learning success for short-term 
and long-term retention.

The statistical results supported the hypotheses that there were significant positive relationships between the number of words students could read (the oral reading score) and the short-term and long-term vocabulary test scores. These results indicated that there was a close relationship between subjects' ability to use graphophonic strategy and their learning achievement. Most interestingly, the result from group $\mathrm{A}$, that long-term test scores correlated more with reading scores than short-term test scores did, suggested that using graphophonic strategy was particularly helpful in memorizing words in the long run. However, another hypothesis, that there was a significant negative relationship between the time spent in reading the list (the reading time) and vocabulary test scores, was supported only by the statistical result of group A. After analysis, the data of group B indicated that the time spent in reading the vocabulary list did not necessarily reflect group B subjects' ability to use graphophonic strategy. Thus the non-significant result of group B should not overrule the original hypothesis that there was a relationship between the ability to use graphophonic strategy and the learning achievement.

Since six out of eight statistical correlations were significant, it seemed safe to conclude that using graphophonic strategy could help Chinese students learn words more effectively. Although it was unknown whether the subjects who knew graphophonic correspondences were also superior in overall vocabulary skills and used every possible strategy in learning the target words, it was certain that 
subjects who did not use graphophonic strategy were more likely to learn less and remember less. Also, although this study measured the availability of a graphophonic strategy instead of actual use of such a strategy in learning, the results at least suggested that the subjects who had graphophonic skills available were better learners than people who did not.

\section{IMPLICATION FOR EFL TEACHING}

From the results of this study, a very curious phenomenon can be observed. Even after five or six years learning English, many Chinese students still can not read an English word without the teacher first reading the word to them. Chinese students are very familiar with learning characters by rote, associating the visual shape of a word with the sound and its meaning; thus if they can get the pronunciation of an English word, many of them will associate the shape of the word with its pronunciation without knowing the relationship between the composing letters and sound. These students usually can survive in high school English classes, where all the vocabulary is orally read by teachers. However, vocabulary items in college textbooks and technical material do not come with pronunciations. The students who do not know graphophonic correspondences are thus deprived of any phonological access to new words, and must use other, non-phonological strategies in vocabulary learning.

However, the fact that some subjects knew graphophonic correspondences indicated that developing graphophonic awareness is possible for Chinese students 
even though their first language does not require that skill. Because most English teachers in Taiwan do not pay much attention to students' development of graphophonic awareness, students are left to acquire this knowledge by themselves. Those who cling to the traditional Chinese method of rote learning without acquiring the knowledge of graphophonic correspondences in English may waste time and energy in learning English words. Thus the responsibility of an English teacher should include teaching graphophonic strategy to students.

\section{SUGGESTIONS FOR FURTHER RESEARCH}

Three questions could be studied further. First, it could be useful to sort out the graphophonic skill variable from among the overall skills. This study was unable to compare the effectiveness of graphophonic strategy versus the visual strategy (or any other strategies) because each student might use many skills in their learning task, either consciously or unconsciously. If a research method could be developed to compel the use of graphophonic strategy without the interference of other available strategies, it would help in further understanding the role of graphophonic skills in learning vocabulary.

Second, it might be interesting to investigate the effectiveness of any of the non-graphophonic strategies for learning and remembering words. This study only shows that students will learn less efficiently without knowing graphophonic correspondences, but it doesn't prove that graphophonic strategy by itself is superior compared to other strategies. As mentioned in Chapter V, non- 
graphophonic strategies were speculated to account for some anomalies in the data sets, including the outliers in the scatterplots and the group difference between groups A and B. Further research could be done on the effectiveness of visual or rote-learning, either alone or compared to graphophonic strategy by itself. It would also be useful to investigate the best combination of strategies for learning English words.

The third, and most important question for further study, is how to teach adult students graphophonic correspondences. Not many ESL or EFL teachers are trained in teaching the correspondences between sound and print. Without the help of professionals, rule-teaching can turn out to be mechanical lettersubstitution exercises. Further research should be done on the proper way to teach graphophonic strategy in learning words. If all the above mentioned questions could be answered, Chinese students may be able to receive the fullest advantage from both their traditional learning method and from the graphophonic strategy. 


\section{REFERENCES}

Baddeley, A. \& Lewis, V. 1981. Inner Active Processes in Reading : The Inner Voice, the Inner Ear, and the Inner Eye. In Lesgold, A. M. \& C. A. Perfetti (Eds) Interactive Processes in Reading. New Jersey: Lawerence Erlbaum Associates. 107-129.

Baron, J. 1973. Phonemic Stage not Necessary for Reading. Quarterly Journal of Experimental Psychology, 25, 241-246.

Baron, J. 1977. Mechanisms for Pronouncing Printed Words: Use and Acquisition. in Laberge D. \& Samuels, S. J. (Eds.) Basic Processes in Reading: Perception and Conception. New Jersey: Lawerence Erlabum Associates.

Baron, J. \& Treiman, R. 1980. Use of Orthography in Reading and Learning to Read. In Kavanagh, J. F. \& Venezky, R. L. (Eds.), Orthography, Reading, and Dyslexia. Maryland: University Park press.

Biederman, I. and Tsao Y. 1979. On Processing Chinese Ideographs and English Words: Some Implications from Stroop-Test. Cognitive Psychology. 11: $125-132$.

Brooks, L. 1977. Visual Pattern in Fluent Word Identification. In Reber, A. S. \& Scarborough, D. S. (Eds.), Towards a psychology of reading: Proceedings of the CUNY Conferences. New Jersey: Lawrence Erlbaum and Associates.

Conrad, R. 1964. Acoustic Confusion in Immediate Memory. British Journal of Psychology. 55, 75-84.

Field, M. L. 1985. A Psycholinguistic Model of the Chinese ESL Reader. On TESOL '84. p. 171-82.

Fischer-Kohn, E. 1986. Teaching Close-Reading for ESL/EFL: Uses and Abuses. Paper Presented at the Annual Meeting of the Teachers of English to Speakers of other Languages. 
Gleitman, L. R. and Rozin, P. 1977. The Structure and Acquisition of Reading I: Relation between Orthographies and the Structure of Language. In Reber, A. S. and Scarborough, D. L. (Eds.). Toward a Psychology of Reading: The Proceedings of the CUNY Conference. New Jersey: Lawerence Erlbaum Associates. 1-53.

Hardyck, C. D. \& Petrinovich, L. F. 1970. Subvocal Speech and Comprehension Level as a Function of the Difficulty Level of Reading Material. Journal of Verbal Learning and Verbal Behavior 9, 647-652

Hatta, T. 1977. Recognition of Japanese Kanji in the Left and Right Visual Field. Neuropsychologia 42, 163-166.

Kimura, D. 1973. The Asymmetry of the Human Brain. Scientific American, 228, 70-78.

Levy, B. A. 1975. Vocalization and Suppression Effects in Sentence Memory. Journal of Verbal Learning and Verbal Bahavior. 14, 304-316

Liberman, I. Y., Shankweiler D., Liberman, A. M., Fowler, C., \& Fischer, W. 1977. Phonetic Segmentation and Recoding in the Beginning Reader. In Reber, A. S. \& Scarborough, D. L. (eds) Toward a Psychology of Reading. New Jersey: Lawrence Erlbaum Associates. 207-225.

Liu, S. A. 1978. Decoding and Comprehension in Reading Chinese. In CrossCultural Perspectives on Reading and Reading Research, Newark, Delaware: International Reading Association. 144-145.

Osborne-Wilson, C., Sinatra, R. and Baratta, A. N. 1989. Helping Chinese Students in the Literacy Transfer Process. Journal of Reading 32(4):330-36.

Mishkin, M., \& Forgays, D. G. 1952. Word Recognition as a Function of the Retinal Locus. Journal of Experimental Psychology, 43, 43-48.

Rozin, P., Ponitsky, S., \& Sotsky, R. 1971. American Children With reading Problems Can Easily Learn to Read English Represented by Chinese Characters. Science, 171, 1264-1267.

Scovel, J. 1983. English Teaching in China: A Historical Perspective. Language Learning and Communication, 1 (2): 105-110. 
Shwedel, A. M. 1983. Must We Use Phonology to Read? What Chinese Can Tell Us. Journal of Reading 26(8):707-13.

Stroop, J. R. 1935. Studies of Interference in Serial Verbal Reactions. Journal of Experimental Psychology, 18, 643-662.

Sperry, R. W., Gazzaniga, M. S., \& Bogen, J. E. 1969. Interhemispheric Relationships: The Neocoritical Commissures; Syndromes of Hemispheric Disconnection. In P. H. Vinken \& G. W. Bruyn (Eds.), Handbook of clinical neurology (vol. 4). Amsterdam: North-Holland Publisher.

Taylor, I. 1987. Scripts and Reading Research. Interchange, 18(1-2):78-88.

Tsao, Y-C., Feustel, T., \& Soseos, C. 1979. Stroop Interference in the Left and Right Visual Fields. Brain and Language, 8, 367-371.

Tsao, Y-C., Wu, M. F. \& Feustel, T. 1981. Stroop Interference: Hemispheric Difference in Chinese Readers. Brain and Language, 13, 372-378.

Treiman, R. A. and Baron, J. 1981. "Speech Recoding in Silent Reading: A Comparison of Chinese and English. Journal of Chinese Linguistics. 9, 116-125.

Treiman, R. A. \& Baron, J. 1983. Individual Differences in Spelling: the Phoenician -- Chinese Distinction. Topics in Learning and Learning Disabilities 3(3). 33-40.

Tzeng, O. J. L. 1983. Cognitive Processing of Various Orthographies. In Mae Chu-Chang (ed) Asian and Pacific American perspectives in Bilingual education. New York: Teachers College Press. 73-96.

Tzeng, O. J. L. and Hung, D. 1980. Reading in a Nonalphabetic Writing System: some Experimental Studies. In Kavanagh, J. F. (ed) Orthography, Reading, and Dyslexia. Baltimore, Maryland: University Park Press. 137-153.

Tzeng, O. J. L., Hung, D. L. and Cotton, B. 1979. Visual Lateralisation Effect in Reading Chinese Characters. Nature vol. 282. p.499-501.

Wang, A. T. and Earle, R. A. 1972. Cultural Constraints in Teaching Chinese Students to Read English. Reading Teacher. 25(7):663-69.

Wang, W. S-Y. 1981. Language Structure and Optimal Orthography. In Tzeng, O. J. L. \& Singer, H. (Eds.), Perception of Print: Reading Research in Experimental Psychology. New Jersey: Erlbaum. 
Zhou, M. 1988. Script Effects and Reading Strategies: Ideographic Language Readers Vs. Alphabetic Language Readers in ESL. Thesis for the Degree of M. A. in TESOL. Portland State University. 
APPENDIX A

THE VOCABULARY LEARNING LIST 
APPENDIX A

THE VOCABULARY LEARNING LIST

$\begin{array}{llll}\text { 1. } & \text { grudge } & 20 . & \text { dungeon } \\ 2 . & \text { frolic } & 21 . & \text { drudgery } \\ \text { 3. } & \text { lunge } & 22 . & \text { surge } \\ \text { 4. } & \text { herbivore } & 23 . & \text { bruise } \\ \text { 5. } & \text { cinch } & 24 . & \text { follicle } \\ \text { 6. } & \text { scuffle } & 25 . & \text { bluff } \\ \text { 7. } & \text { nodule } & 26 . & \text { truant } \\ \text { 8. } & \text { impetus } & 27 . & \text { cranium } \\ \text { 9. } & \text { oblivion } & 28 . & \text { rapture } \\ \text { 10. } & \text { fortitude } & 29 . & \text { orator } \\ 11 . & \text { narcotic } & 30 . & \text { sagacity } \\ \text { 12. } & \text { munitions } & 31 . & \text { gallantry } \\ \text { 13. } & \text { gaze } & 32 . & \text { throng } \\ \text { 14. } & \text { rind } & 33 . & \text { trinket } \\ 15 . & \text { havoc } & 34 . & \text { referee } \\ 16 . & \text { ferocity } & 35 . & \text { grit } \\ 17 . & \text { parody } & 36 . & \text { stint } \\ 18 . & \text { scourge } & 37 . & \text { armistice } \\ \text { 19. } & \text { serum } & \text { magistrate }\end{array}$


APPENDIX B

SAMPLE OF THE VOCABULARY LEARNING BOARD 
havoc 廣佈的損害。 弉震

widespread damage or serious disorder

\section{example:}

\section{The earthquake caused}

havoc on the city last night. Half of the houses were destroyed in fire and explosions. 


\section{APPENDIX C}

THE SHORT-TERM VOCABULARY RECALL TEST 
1. Mary fell off the stair and got some on her left leg.
A. grits
B. bruises
C. scuffles
D. bluffs
E. truants

2. There was a brief before the police put the handcuffs on the criminal.
A. cinch
B. scourge
C. cranium
D. scuffle
E. nodule

3. Henry lost his right leg in a war. He needed a lot of to overcome his depression.
A. grit
B. gaze
C. surge
D. impetus
E. trinket

4. The present conflict might provide fresh for peace talks.
A. stint
B. impetus
C. gallantry
D. defeat
E. oblivion

5. The child's stayed on the beautiful doll that could talk and walk.
A. rind
B. serum
C. follicle
D. orator
E. gaze 
6. If a thing is in , it is not at rest.
A. stint
B. frolic
C. rapture
D. scuffle
E. motion

7. He felt a of anger when he saw his girlfriend kissing the other man.
A. throng
B. rapture
C. surge
D. parody
E. motion

8. John told his daughter that he would beat her if she was not home after ten o'clock, but she thought it was only a
A. bluff
B. grudge
C. frolic
D. havoc
E. narcotic

9. They planned their life together during the of their honeymoon.
A. lunge
B. ferocity
C. dungeon
D. rapture
E. bruise

10. She arrived at the university for a three month as a lecturer.
A. grudge
B. munitions
C. disorder
D. sagacity
E. stint 
11. This innocent baby would not hold any his parents. against the people who killed
A. referee
B. armistice
C. rapture
D. grudge
E. fortitude

12. He made a at his opponent with his sword.
A. frolic
$B$. lunge
C. frolic
D. stint
E. drudgery

13. We should invite Mary to speak to the students next time. She is the best in school and the students enjoy her speech.
A. drudgery
B. sagacity
C. orator
D. herbivore
E. paradise

14. He was awarded a medal and one hundred thousand dollars for his in the battle.
A. dungeon
B. drudgery
C. gallantry
D. hesitation
E. bluff

15. The burglars left the room in great
A. throng
B. impetus
C. ferocity
D. disorder
E. scourge 
16. This author is a genius. All of his works are real modern verse, not of any kind.
A. surge
B. trinket
C. scuffle
D. disorder
E. parody

17. The police woman arrested the young man when he tried to sell on the street.
A. follicle
B. serum
C. rapture
D. narcotics
E. rind

18. The is the part of the skull that covers the brain.
A. motion
B. cranium
C. trinket
D. lunge
E. truant

19. The called stop when one of the ball players was pushed down on the floor by the other player.
A. armistice
B. paradise
C. magistrate
D. orator
E. referee

20. That poor little child was put into a broke into the castle and rescued him. for three days before his father
A. dungeon
B. grudge
C. cranium
D. bruise
E. serum 
21. I found the throwing stones in the river. He had been out of school for over a month.
A. magistrate
B. trinket
C. referee
D. truant
E. orator

22. These forests are a hunter's
A. cranium
B. paradise
C. gallantry
D. trinket
E. nodule

23. The two governments decided to have an after ten long years of war.
A. oblivion
B. armistice
C. orator
D. impetus
E. absence

24. The young couples decided to buy some for their wedding because they could not afford any expensive jewelry.
A. narcotics
B. nodules
C. trinkets
D. munitions
E. motions

25. The wise man settled the problem between the two families with his
A. oblivion
B. fortitude
C. gaze
D. havoc
E. sagacity 
26. The government has suffered a serious
A. scuffle
B. oblivion
C. parody
D. defeat
E. armistice

27. John is bald. No hair has grown out of the on his head for years.
A. munitions
B. narcotics
C. follicles
D. scuffles
E. trinkets

28. The flood brought to this county. Many of the crops in the field were destroyed.
A. impetus
B. havoc
C. surge
D. ferocity
E. frolic

29. With , Richard tried to support his family with his sick wife and three little children.
A. oblivion
B. scourge
C. ferocity
D. fortitude
E. armistice

30. The is trying to think of a proper judgement for that difficult case.
A. sagacity
B. orator
C. magistrate
D. grudge
E. truant 
31. I will eat the watermelon only if you get rid of the for me.
A. cranium
B. rind
C. serum
D. throng
E. grit

32. Without a moment's she jumped into the river after the child.
A. hesitation
B. frolic
C. munition
D. lunge
E. sagacity

33. The mother told her son that a horse is a . It will not eat any meat.
A. herbivore
B. bruise
C. drudgery
D. cinch
E. follicle

34. The children were having a at home when their parents went out.
A. frolic
B. havoc
C. gaze
D. bluff
E. rapture

35. Some people believe that cancer is the of modern civilization.
A. lunge
B. stint
C. scourge
D. follicle
E. parody 
36. This old custom had sunk into modern world generally do not know of it. a long time ago. People in the
A. magistrate
B. sagacity
C. defeat
D. havoc
E. oblivion

37. It is very important to have a sufficient supply of during the war; otherwise we will lose.
A. hesitation
B. munitions
C. narcotics
D. rinds
E. nodules

38. There was a of people trying to buy tickets for the football game between our team and last year's champion team.
A. throng
B. motion
C. gaze
D. dungeon
E. rind

39. There are some on the root of the plant. They look ugly but may not be very harmful.
A. scuffles
B. bruises
C. trinkets
D. nodules
E. follicles

40. John hit his opponent with such that his opponent could not walk for three days.
A. sagacity
B. fortitude
C. ferocity
D. drudgery
E. gallantry 
41. Her son has always been good at science. Solving these math problems should be a for him.
A. cinch
B. grudge
C. lunge
D. bluff
E. rapture

42. Mary thought that her career as an office clerk was boring. All the work she did every day was tiresome
A. drudgery
B. parody
C. munition
D. throng
E. scourge

43. Don't worry. He will not be in danger after the injection of some
A. havoc
B. impetus
C. hesitation
D. cranium
E. serum 